\title{
Given the continuing dispute over the role of genetic abnormalities and protracted mitochondrial respiratory dysfunction in carcinogenesis, what is the core underlying entity?
}

\begin{abstract}
Background: For a long time, oncologists have believed that the main factors underlying carcinogenesis are related to genetic abnormalities or protracted mitochondrial respiratory dysfunction, which are core reasons for carcinogenesis. Thus, I want to discuss how to intend to demonstrate that mitochondria respiratory dysfunction might be the true causal factor underlying carcinogenesis by presenting evidence obtained in experiment in which specific herbal medicines are used to inhibit the oxygen respiration of cancer cells and cancer re-differentiation-inducing treatment is exploited to return cancer cells to normal cells.
\end{abstract}

\section{Methods:}

First project: I have discovered a specific herbal medicine that selectively affects cancer mitochondrial respiration function, and if this herbal medicine has an impact on the hallmarks of cancer, then the results would demonstrate that carcinogenesis originates from mitochondrial respiratory dysfunction.

Second project: I exploited cancer re-differentiation-inducing treatment developed 5 years ago.

So I could noninvasively treat cancer patients. This treatment was highly successful and didn't require chemotherapy and radiotherapy.

Results: The herbal medicine (Sun Advance) had an impact on most of the hallmarks of the cancer in basic medical experiments. Furthermore, successful results were obtained for cancer patient treated with the re-differentiation-inducing treatment.

Conclusion: Carcinogenesis is a form of mitochondrial respiratory dysfunction. Therefore, primary cancer prevention and recurrence prevention programs should advocate for life-style changes and re-differentiation inducing treatment.

Keywords: Summation of genetic abnormalities, protracted mitochondrial $\square$ respiratory dysfunction, genetic instability, herbal medicine specifically to inhibit cancer cell respiration, defective immune-surveillance, re-differentiation-inducing treatment
Volume I Issue 2 - 2018

\section{Tsuneo Kobayashi}

International cancer prevention center, Japan

Correspondence: Tsuneo Kobayashi, International cancer prevention center, Chiba city, 3-2I-I, Takasu, Mihamaku, Chiba city 26I-0004, Japan, Tel 043-306-26 I I, Fax 043-279-42 I I, Emailft1992@vega.ocn.ne.jp

Received: June 01, 2017| Published: April 30, 2018

\section{Introduction}

Sixty years ago, Otto Warburg initially proposed that aerobic glucose fermentation was an epiphenomenon representing one of the most fundamental problems in cancer cell physiology ${ }^{1}$ that is impaired or damaged respiratory dysfunction. But many oncologists believe that carcinogenesis originates because of a number of genetic abnormalities. Sidney Weinhouse ${ }^{2,3}$ and Alan Aisenburg ${ }^{4}$ have criticized Warburg's opinion. Although, Peter Pedersen ${ }^{5}$ and Thomas Seyfried et al. ${ }^{6}$ have shown that protracted mitochondrial respiratory dysfunction is the main reason for underlying carcinogenesis. ${ }^{6}$ However, much of the confusion surrounding the origin of cancer arises from absence of a unifying theory that can integrate the diverse observation on the nature of the disease. ${ }^{7}$ Thomas N Seyfried ${ }^{6}$ showed that the majority of cancer gene defects could arise as downstream epiphenomenon of tumor progression, rather than as cancer causes. ${ }^{6}$ Although almost 700 targeted therapies have been developed from cancer genome projects, a cure for patients with solid tumors, has not been developed based on these strategies. ${ }^{8}$ James Watson, the Novel Prizer who discovered double stranded DNA, recently suggested that more attention should be paid to the metabolism of cancer. ${ }^{9}$ Damage to mitochondria which causes a loss of cytochrome $\mathrm{C}$ from the associated mitochondria, is understood to which subsequently lose the ability to undergo apoptosis. Hybridization experiments have confirmed that normal mitochondria have the ability to overwhelm cancer mitochondria.

Koura $\mathrm{H}^{10}$ Israel BA \& Schaffer $\mathrm{WI}^{11}$ experimented with the hybridization of enucleated normal cells with cancer cells and they showed that the hybridized cell (cybrids) reverted to normal cells because the power of normal mitochondria were sufficiently powerful to overtake the nuclear DNA of cancer cells. Researchers who insist that carcinogenesis is induced by the accumulation of genetic abnormalities have neglected the results of these hybrids (cybrids) 
experiments as described bellow (Figure 1). ${ }^{10-12}$ Thomas N Seyfried ${ }^{6}$ reported that normal mitochondria functions maintains a differentiated state, thereby suppressing carcinogenesis, whereas dysfunctional mitochondria can enhance dedifferentiation, thereby facilitating carcinogenesis. ${ }^{13-16}$ However, I believe that mitochondria involved in not only metabolic diseases, but also development diseases because mitochondria play a key role in cell differentiation. ${ }^{17,18}$ Sesaki $\mathrm{H}$ et al. ${ }^{18}$ have reported the direct proof that is(S)from matured mitochondria changed to degraded or fragmented mitochondria by oncogenic MAPK signaling, vice versa, from fragmented mitochondria to matured mitochondria by oncogenic MAPK signaling inhibition. ${ }^{19}$ Many researchers have intensively studied cancer and reported that it is induced by nuclear DNA or mitochondria dysfunction and these findings are inconsistent as the results of(SThomas Seyfried ${ }^{20}$ who reported the correlation between the oncogenic paradox and Warburg effect (Figure 2). These authors reported that carcinogenesis is a protracted form of mitochondrial dysfunction and indicated that genome abnormality occurs as down-stream of mitochondrial degradation. Based on my studies, I believe that this conclusion might also be true from my study. I have found a specific herbal medicine, Sun Advance (IMHC, Chiba city, Japan) although it is a mixture of 18 herbs.(SI have investigated their molecular basis for 10 years, nevertheless, I could not found any molecular basis, but, in this time, I made my mind that I manipulated it as a single medicine in further scientific research on this herbal medicine. This herbal medicine selectively inhibits oxygen consumption on Ehrlich ascites cancer cells.

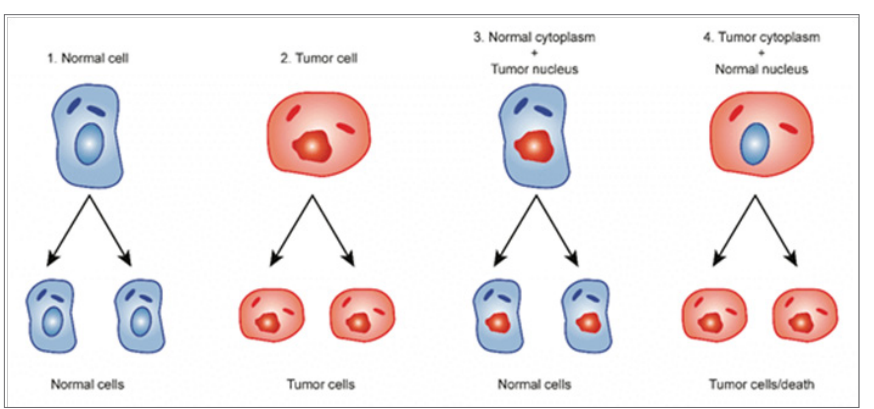

Figure I 3. Cybrids experiment between normal mitochondria and tumor nucleus.

4. Cybrids experiment between tumor mitochondria and normal nucleus.

Enucleated normal cell and cancer cell was hybridized. ${ }^{9}$ As the result, this cybrids produced normal cell.

Normal mitochondrial power overwhelmed nuclear power.

First project: I hypothesized that this herbal medicine could be used to demonstrate that mitochondrial respiratory dysfunction is in reverse the true mechanism underlying carcinogenesis. Many researchers have investigated carcinogenesis based on carcinogenic factors and molecular changes caused by carcinogenesis. However, mitochondria function is closely related to molecular differentiation and morphological differentiation, a number of paradoxical reports has been published. Therefore, I intend to demonstrate that mitochondria respiratory dysfunction might be the true causal factor by utilizing Sun Advance which selectively inhibits the oxygen respiration of cancer cells, and I further intend to show how this herbal medicine (SA) affects the hallmarks of cancer.

Second project: I will attempt to differentiate the damaged dysfunctional mitochondria of cancer cells into normal cell by exploiting re-differentiation-inducing treatment (re-DIT). First, I want to demonstrate the current concept of mitochondria. Although in junior high school textbook, the cocoon-type of mitochondria in cells is shown as dead mitochondria. But our present understanding of organelle is outlined below. Mitochondria represent a dynamic energy delivery tubule network in the cell (Figure 3). However, mitochondria are not only energy centers, but also respiratory centers and differentiation centers. Mitochondria evolved over 1.8 billion years ago, and thus allowing anaerobic cells to evolve into aerobic higher energy eukaryotes that produce 38 ATP. Ninety percent of mitochondrial DNA was inserted into nuclear DNA, and only $10 \%$ of mitochondrial DNA remained in mitochondria by unknown reason. Mitochondria are fundamentally bacterial in origin; therefore, the fusion and fission of molecules occurs easily among mitochondria, ${ }^{16}$ which is a completely different process from eukaryote DNA mitotic cell division. Fertilization in higher animals between an egg and sperm may represent the process when original mitochondria entered into large anaerobic bacterial cell 1.8 billion year ago. Based on this line of thinking, hybridization experiments (cybrids) between enucleated normal cells and cancer cells should be considered as one type of fertilization.

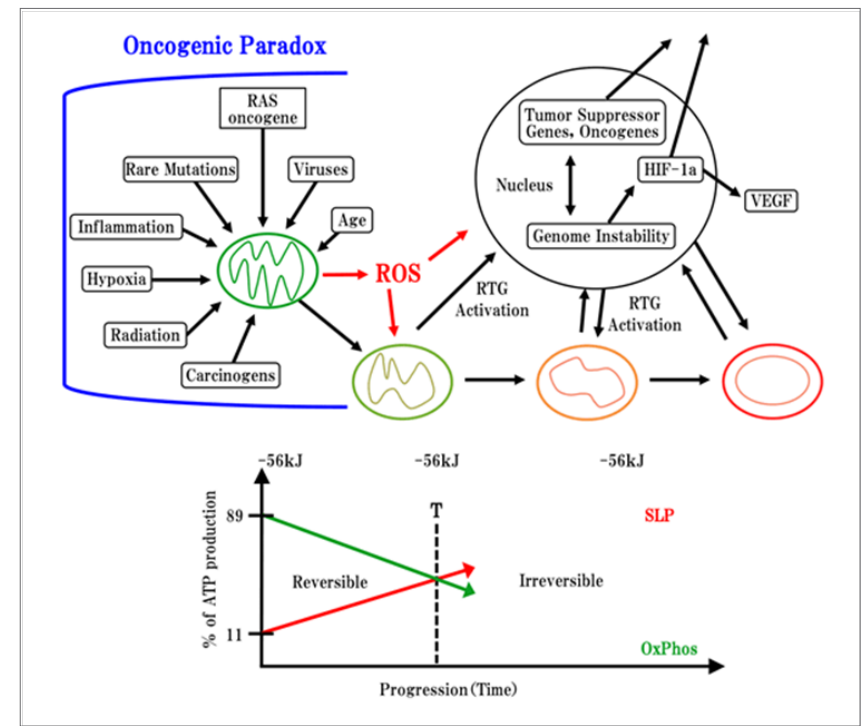

Figure 2 Professor Thomas Seyfried has proposed the matrix between oncogene paradox and genomic instability. In upper left side, many carcinogens are demonstrated that they are inducing not only genomic instability, but also mitochondria ghost like changing or degradation of mitochondria up to the bacterial metabolism. In normal cell, oxidative phosphorylation is about $90 \%$, glucose fermentation is about $10 \%$.

Following to carcinogenesis, oxidative phosphorylation decreased under $40 \%$ and glucose fermentation increased to over $60 \%$. The sovereignty of respiration system changed from mitochondrial respiration system to bacterial respiration system, consequently, changing from eukaryotic cell division to bacterial cell division.

1. I discovered an herbal medicine (Sun Advance hereafter referred to as SA) that selectively inhibits the oxygen respiration of Ehrlich ascites cancer cells via combination of albumin, $\alpha$-and $\beta$-globulin and palmitate. Moreover, I have investigated the factors that cause albumin to decrease and $\alpha-, \beta-, \gamma$-globulin fraction to increase according to the progression of cancer $^{21}$ and addressed the following questions, 


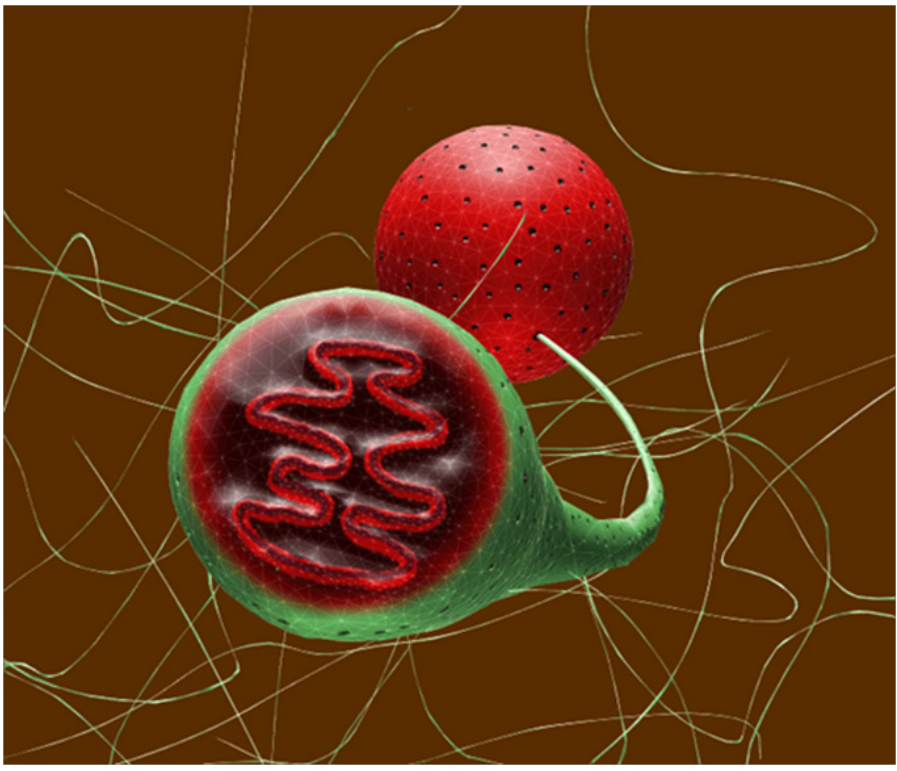

Figure 3 Mitochondria is not cocoon, but a dynamic energy delivery network in the cell (Figure 3) utilizing endoplasmic reticulum. ATP produced from mitochondria can easily deliver all places within the cell.

a. what are the effects of a combining albumin $\left(10^{-4} \mathrm{M}\right)$ (A)+palmitate $\left(10^{-5} \mathrm{M}\right)(\mathrm{P})+$ herbal medicine(SA:(S) $(35 \mu \mathrm{g}) \square$ Figure 4). Oxygen consumption experiments were performed using cooccurring human-albumin $\left(10^{-4} \mathrm{M}\right)(\mathrm{A})$ and palmitate $\left(10^{-5} \mathrm{M}\right)(\mathrm{P})$ and $\mathrm{SA}(35 \mu \mathrm{g})(\mathrm{A}+\mathrm{P}+\mathrm{S})$, then the oxygen consumption of Ehrlich ascites cells was selectively inhibited, however, inhibition did not occur with SA alone(S) or with the combination of SA and albumin $(A+(S)$ ). SA bottle is shown below (Figure 5).

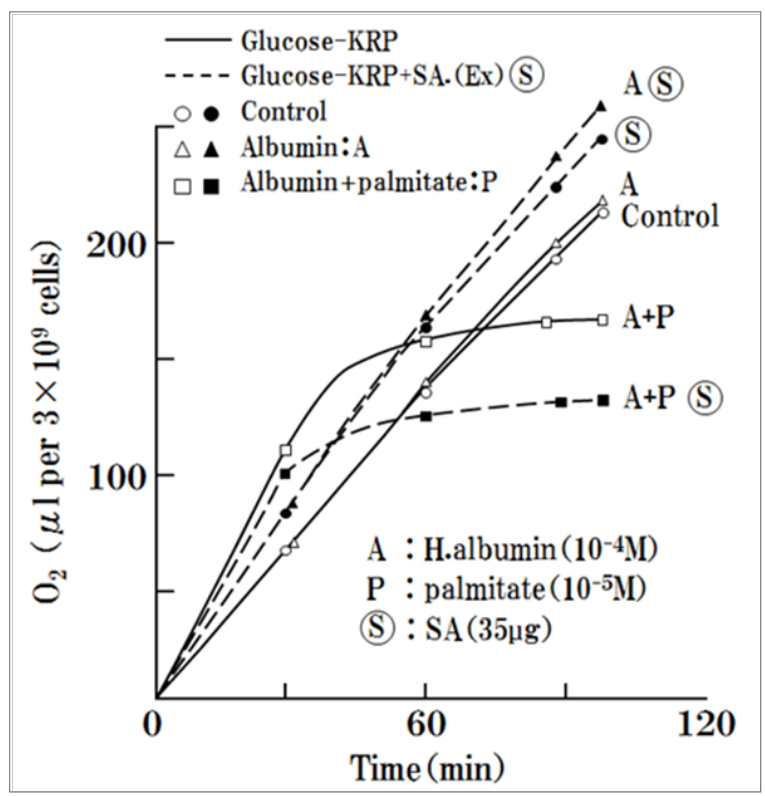

Figure 4 Effect of $\mathrm{SA}(35 \mu \mathrm{g})(\mathrm{S})$ and human albumin $\left(10^{-4} \mathrm{M}\right)(\mathrm{A})+\mathrm{FFA}$ palmitate $\left.10^{-5} \mathrm{M}\right)(\mathrm{P})$ on Ehrlich ascites tumor cells( $10^{9}$ cells). Each sample includes 10 samples tested and data are averaged. Ehrlich ascites cell are cultured in the incubator at $37^{\circ} \mathrm{C}$. Oxygen respiration of Ehrlich as cites cancer was stopped 30 minutes after the addition of $35 \mu \mathrm{g} \mathrm{SA}$.

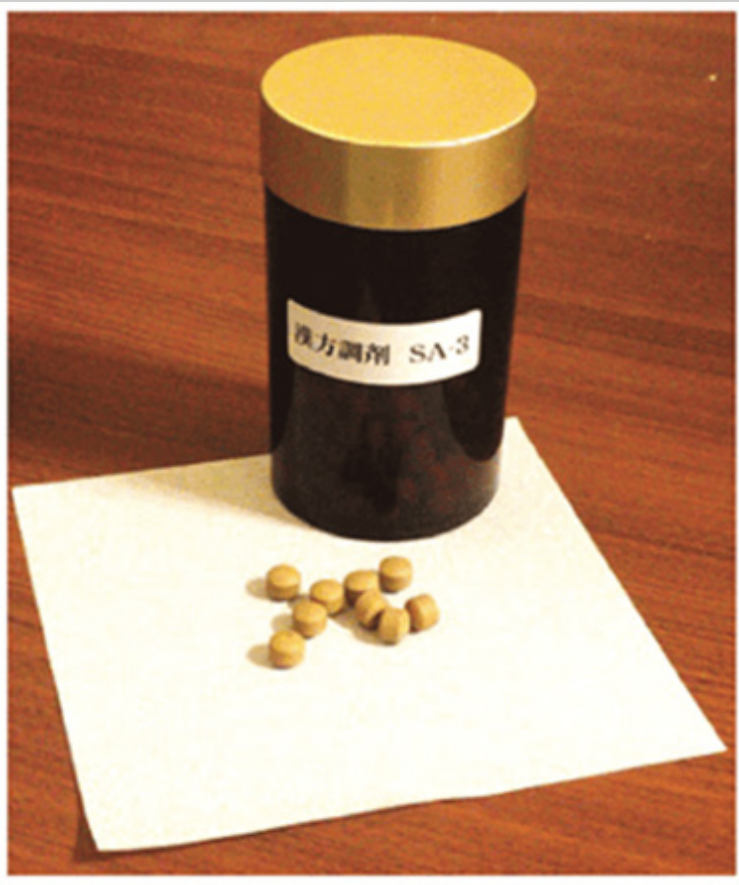

Figure 5 This herbal medicine is manufactured in IMHC clinic (Chiba city, Japan). Sun Advance is 18 kind mixtures of herbs, tablet type of medicine which has a selective inhibiting effect on neoplasm mitochondrial respiration.

b. What are the combined effects of $\alpha$-globulin $(0.15 \%)(\alpha)+$ palmitate $\left(2 \times 10^{-3} \mathrm{M}\right)(\mathrm{P})$ :(Figure 6). The respiration of Ehrlich ascites cells was only selectively inhibited in the cases of $\alpha$-globulin $(\alpha)$ and palmitate(P) or $\alpha$-globulin $(\alpha)$ palmitate $(\mathrm{P})$ $+(S)$ These data show that the SA has the possibility of strongly inhibiting the mitochondrial respiration of cancer cells when used in combination with albumin or $\alpha$-globulin and palmitate.

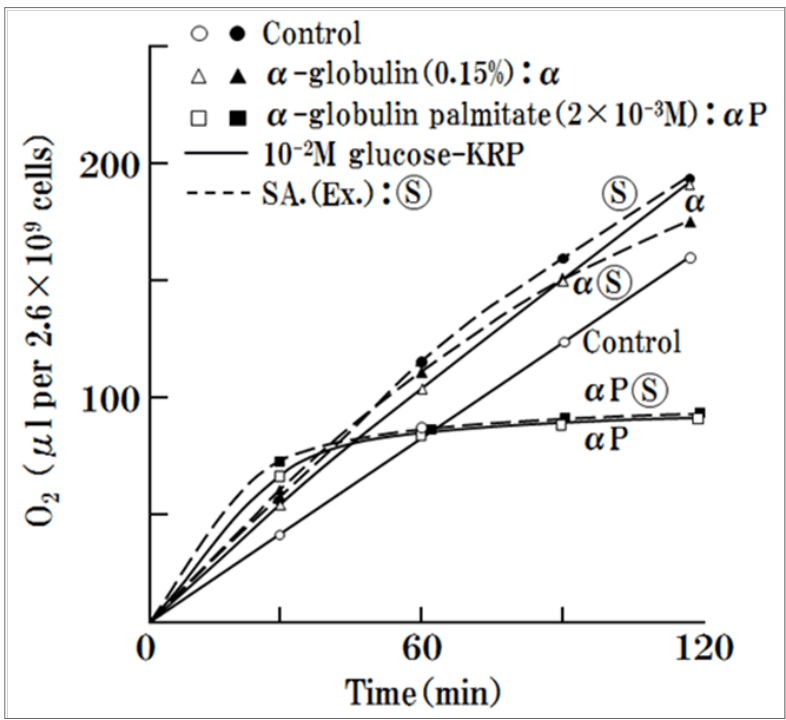

Figure 6 Interaction of SA (S) and $\alpha$-globulin-FFA ( $\alpha \mathrm{P})$ in oxygen uptake of Ehrlich ascites tumor cells.

$\alpha$-globulin $(0.15 \%)(\alpha)$, palmitate $\left(2 \times 10^{-3} \mathrm{M}\right)(\mathrm{P})$ and $\mathrm{SA}(\mathrm{S})(35 \mu \mathrm{g})$ were utilized. SA (.Ex) means which was mixture of $S A$ and mix-juice of apple and cucumber. Ehrlich ascites cell are cultured in the incubator at $37^{\circ} \mathrm{C}$. Oxygen respiration was stopped 30 minutes after the addition of $35 \mu \mathrm{g}$ SA. 
c. What are the effects of combining $\beta$-globulin $(0.4 \%)$ ( $\beta$ )Spalmitate $(2 \times 10-3 \mathrm{M})(\mathrm{P})+\mathrm{SA}(35 \mu \mathrm{g}$ :S) (Figure 7). These data show that SAS has a possibility to work strongly on damaged mitochondrial oxygen respiration with the combination of Bglobulin $(\beta)$ and palmitate $(\mathrm{P})$. The combination of albumin (A) $+\alpha$-or $\beta$-globulin + palmitate (P) + SA(S) smoothly inhibited the respiration of Ehrlich ascites cells after 30 minutes of incubation.

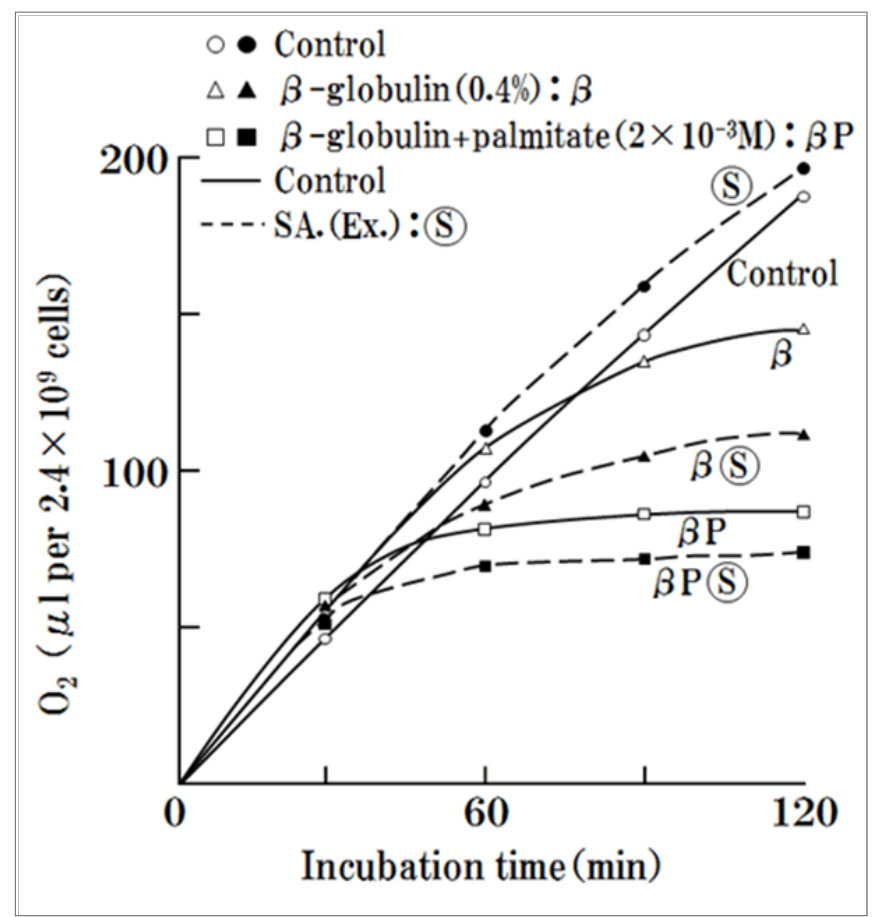

Figure 7 Effect of SA $+\beta$-globulin + palmitate $(2 \times 104 M)$ on respiration of Ehrlich ascites tumor cells.

$\beta$-globulin ( 0.4\%), palmitate( $2 \times 104 \mathrm{M}), \mathrm{SA}(\mathrm{Ex}$ : 50/ 50) Ehrlich ascites cell are cultured in the incubator at $37^{\circ} \mathrm{C}$. Oxygen respiration was stopped 30 minutes after the addition of $35 \mu \mathrm{g}$ SA.

d. What are the combined effects of $\gamma$-globulin $(0.4 \%)$ $(\gamma)+$ palmitate $\left(2 \times 10^{-3} \mathrm{M}\right)(\mathrm{P})+\mathrm{SA}(35 \mu \mathrm{g}$ :(S)):(Figure 8). Figure 8: Ex means the extracted juice of apple and cucumber, SA (Ex) means the mixture of SA and Ex: (50/50). For the treatments combined with $\gamma$-globulin, no effect was observed.

Based on these data, the combination of SA, palmitate (FFA: P) and albumin or $\alpha$-, or $\beta$-globulin co-operatively inhibited the oxygen consumption of Ehrlich ascites cancer cells. Over the short functioning term of 30 minutes, it means perhaps this inhibition may have represented a direct effect of the SA with serum fraction and palmitate on damaged mitochondria. Moreover, normal cells were not affected at all, as shown below. Thus, the observed inhibiting effects were a selective reaction to Ehrlich ascites cells. Here, the effects on normal cells $(\mathrm{C} 3 \mathrm{H}$, mouse kidney cell) of applying the SA are showed below (Figure 9). Ex shows the extracted juice of apple and cucumber.

2. Based on this research, SA likely has a direct effect on mitochondria by inhibiting respiration in cancer mitochondria, especially damaged mitochondria. Here, I show that SA could be effective for most of the hallmarks of carcinogenesis.

1) SA inhibits carcinogenesis by carcinogens.
2) SA inhibits metastasis.

3) SA inhibits and excludes toxo-hormone, which produces cachexia from serum.

4) SA activates the metabolism of lactate

5) SA inhibits carcinogenesis by SV40 (DNA type cancer) virus infection.

6) SA inhibits carcinogenesis, but does not inhibit SV40 virus infection by CV1 cell experiments.

7) SA quantitatively inhibits transformed cancer cell growth curve

8) SA adjusts lipid metabolism

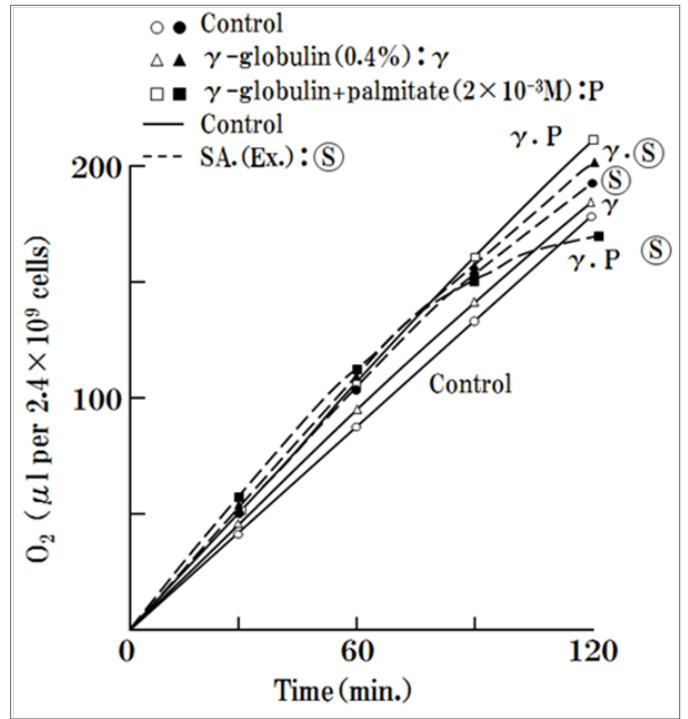

Figure 8 Interaction of SA (Ex: $35 \mu g), \gamma$-globulin ( $0.4 \%$ ) and palmitate( $2 \times 10$ $\left.{ }^{3} \mathrm{M}\right)$ in Ehrlich ascites tumor cells, are tested by Warburg oxygen consumption meter. Ehrlich ascites cell are cultured in the incubator at $37^{\circ} \mathrm{C}$. Oxygen respiration was not stopped with the collaboration with $\gamma$-globulin.

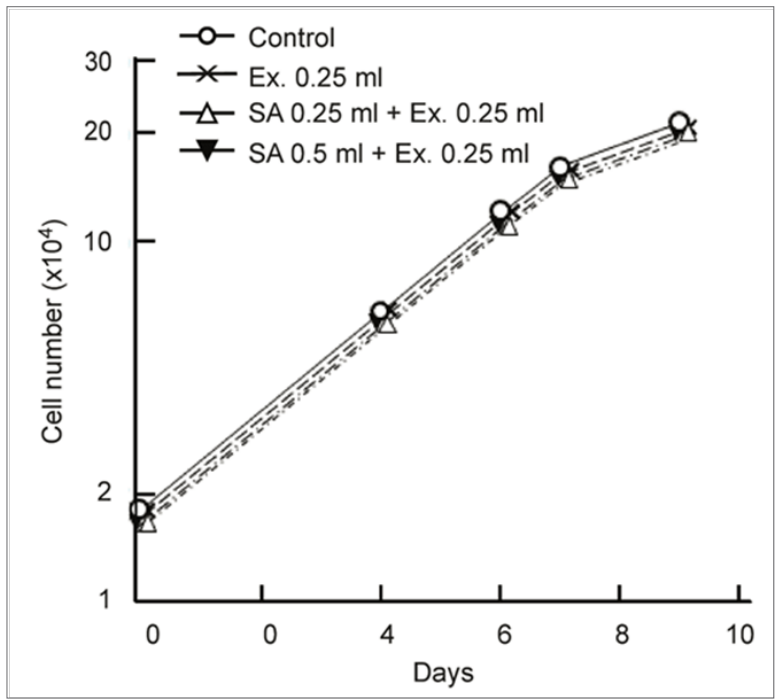

Figure 9 SA was applied on the growth of normal cells $(\mathrm{C} 3 \mathrm{H}$ mouse kidney cell). Ex is the extracted juice of apple and cucumber. Normal kidney cell of $\mathrm{C} 3 \mathrm{H}$ mouse are cultured in the incubator at $37^{\circ} \mathrm{C}$. 
Each topic will be demonstrated stepwise.

i. Chemical carcinogenesis was induced using $0.4 \mathrm{mg}$ of 20-methychorantherene (MC) in mice. ${ }^{22}$ A strong chemical carcinogen was administered via sub-cutaneous injection of $0.1 \mathrm{mg}$ MCx4times. The gray color area indicates the times when SA $(4 \mathrm{mg} / \mathrm{ml})$ was administered to the mouse via oral intake. Black circles indicate tumor-bearing mice. $\mathrm{X}$ indicates death before day 90. Survival is the number of surviving animals at the conclusion of experiment/ the number of animals at the start of the experiment (Figure 10). Longer durations of SA administration corresponded to longer life spans in the mice and reduced number of mice developed cancer, and $10 \%$ suffered from cancer. In the control mice without SA, $80 \%$ of the mice developed cancer, and 10 $\%$ died. These data showed SA had strong inhibiting effects on carcinogenesis.

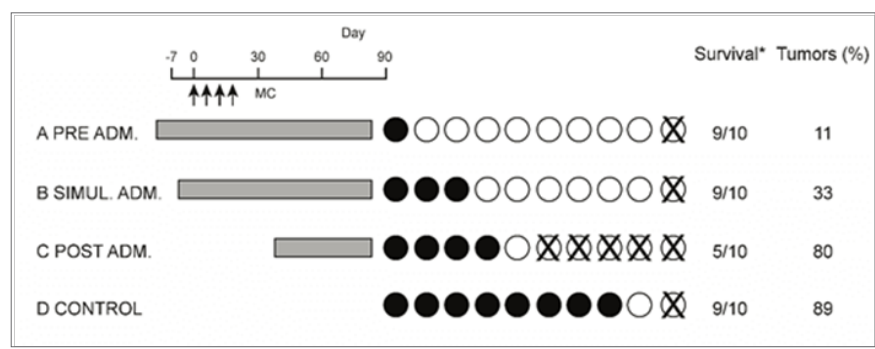

Figure 10 The effect of SA on chemical carcinogenesis which was induced using $0.4 \mathrm{mg}$ of 20-methylchoranthrene (MC) in mice. Inhibitory effect of Sun Advance on 20-methlchoranthrene induced carcinogenesis in mice. Mice were injected s.c. four times with $M C \square(0.1 \mathrm{mg}$ as a single dose). The mice in experimental series A, B and C were given SA $(4.2 \mathrm{mg} / \mathrm{ml})$ in their drinking water (grey color), $\mathrm{D}$ is control.

ii. The inhibiting effects of SA on metastasis were investigated utilizing $\mathrm{C} 3 \mathrm{H}$ mice (each group consisted of 10 mice) and MH134 cancer cells $\left(5 \times 10^{6}\right)$ were injected into the tail veins. After injections for 14 days, metastatic lymph-nodes were counted by autopsy investigation. Strangely and against common sense of herbal medicine, this herbal medicine (SA) was effectively inhibited metastasis according to the dose administered. SA was administered via oral intake in water and it was found to have strong metastasis-inhibiting effects (Figure 11). These results may be gotten from the strong respiratory inhibition by SA on cancer cells.

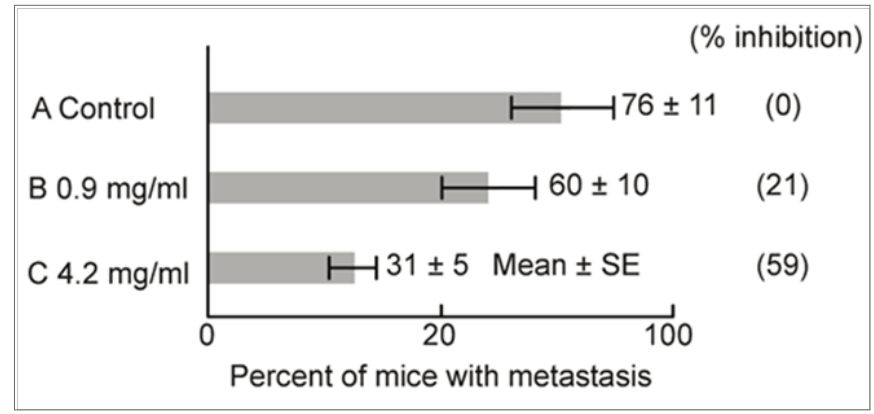

Figure II Inhibitory effect of Sun Advance on metastasis. $5 \times 10^{6}$ of MHI34 cells were injected sc in tails of syngeneic $\mathrm{C} 3 \mathrm{H}$ mice. Mice were given $\mathrm{SA}$ (B: $4.2 \mathrm{mg}$ or C: $0.9 \mathrm{mg} / \mathrm{ml}$ ) per os from day 0 after the injection to day 14 . The number of mice with metastatic lymph nodes was counted on day 14 by autopsy examination.

iii. Herbal medicine (SA) inhibits and excludes toxo-hormone, which produces cachexic patients from their serum (Figure 12). SA was found to effectively inhibit the reduction of serum iron by toxohormone from the data of "The time course of serum iron levels reduced by Toxo-hormone (T.H.)". I have utilized marmots in this experiment because miceis too small to handle in this experiment because 6 times of withdrawal of blood will beyond over $3 \mathrm{ml}$, it is impossible for the little mice experiment.

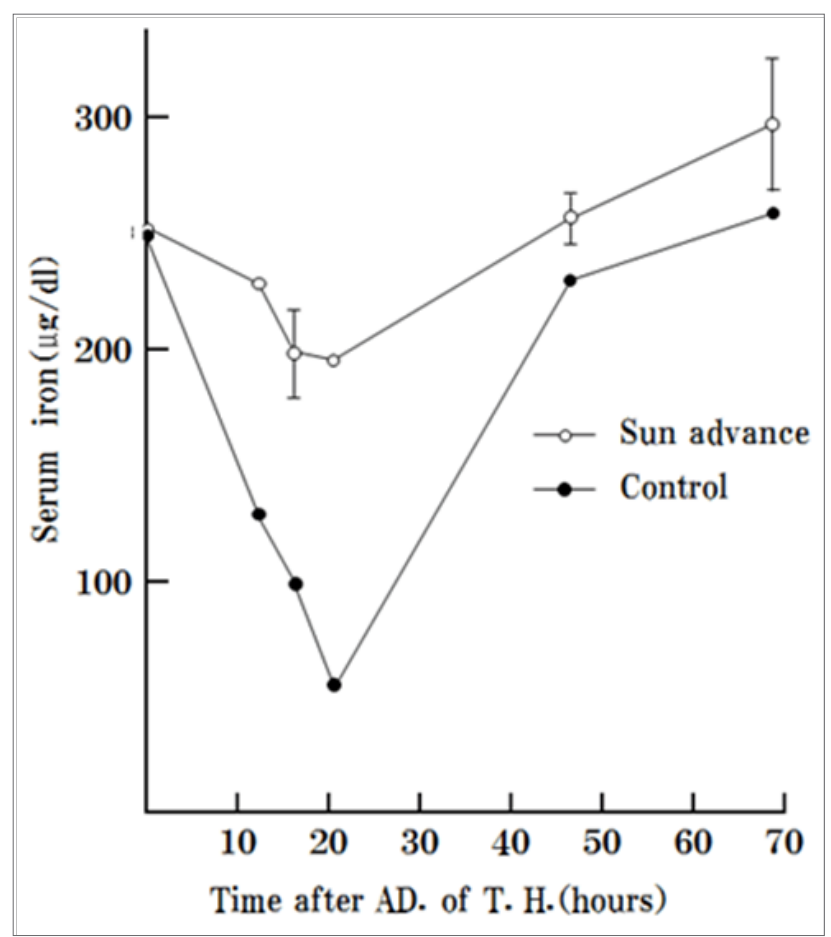

Figure I 2 Time course of serum iron levels reduced by toxo-hormone (T.H.) which was injected into marmot.

Toxo-hormone (T.H.) were extracted from advanced cancer patients and injected into Marmot. Effect of SA was experimented against toxo-hormone. Without SA, serum iron rapidly decreased, but with the addition of SA, serum iron reduction was not so observed. In each experiment, 5 marmots were tested.

iv. Herbal medicine (SA) removes lactate from tissue and consequently serum and finally causes its excretion in urine (Figure 13). These data represent the average data of 5 candidates who are administered SA (1.5g/day) daily, which stopped on day 21. Based on these data, SA remove lactate from tissue, which led to an increase and caused to be increased of lactate in the serum 7 days later and then consequently its excretion in the urine.

a. SV40 cancer virus (DNA virus type) transformation experiments were performed on mouse kidney cells. ${ }^{23}$ An intervention experiment with the addition of SA $(35 \mu \mathrm{g})$ showed that the expression of carcinogenesis was generally reversible. SV40 virus $\left(10^{6} \mathrm{PFU}\right)$ transformation experiments were performed using SA $(35 \mu \mathrm{g})$ on mouse kidney cell $\left(10^{3} /\right.$ dish). Upper panel: SV40 $\left(10^{6} \mathrm{PFU}\right)$ virus only (Figure 14$)$. Lower panel: SV40 $\left(10^{6} \mathrm{PFU}\right)+$ SA $(35 \mu \mathrm{g})$ (Figure 15).

b. Microscopic observations of the black sites under high magnification showed that SA prevented carcinogenesis by inhibiting cell to cell contact (as shown in the next photograph) despite the large exposure of SV40 virus $\left(10^{6} \mathrm{PFU} / 0.2 \mathrm{ml}\right)$ to mouse kidney cells $\left(10^{3} /\right.$ dish) (Figure 16). 


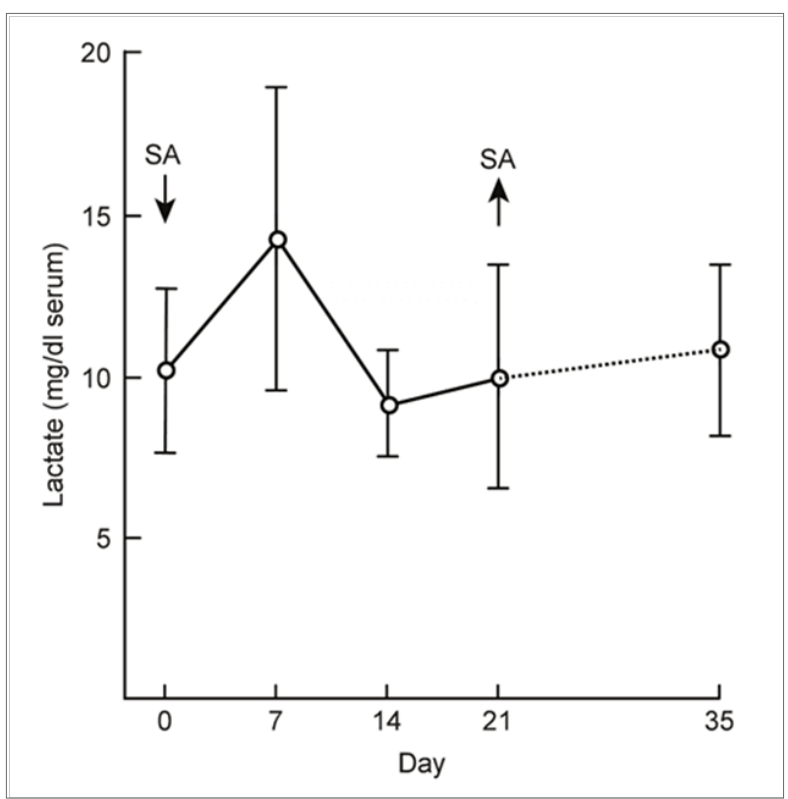

Figure 13 Effect of Sun Advance on lactate in human serum. Five candidates were tested. SA (I.6g) was taken orally on Day 0 and take off on day 21 . By the application of SA, lactate was excreted from the body for the first time and secondary excreted into the urine.

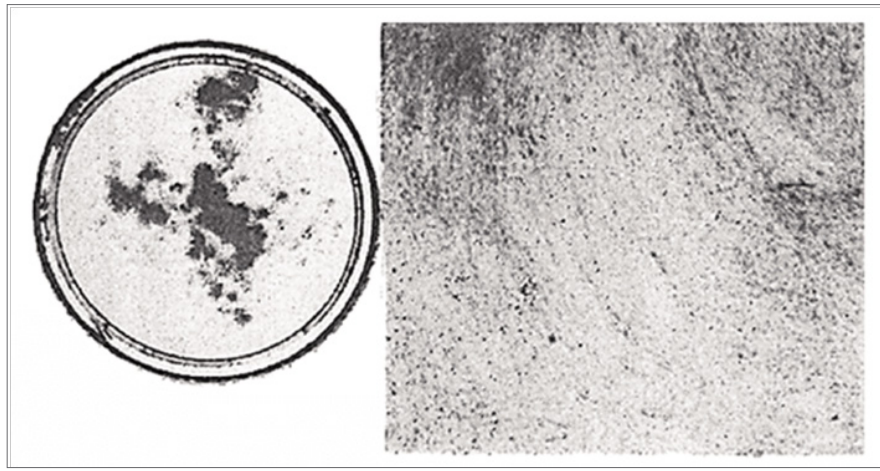

Figure I4 Inhibiting effect of SA on SV40-transformation of mouse cells without SA.C3H mouse kidney cells $\left(10^{3}\right)$ were seeded on one plate in the absence of $35 \mu \mathrm{g} / \mathrm{ml}$ of SA and infected with SV40 virus $\left(10^{6} \mathrm{PFU} / 0.2 \mathrm{ml}\right)$. Aggregation and pile up are observed.

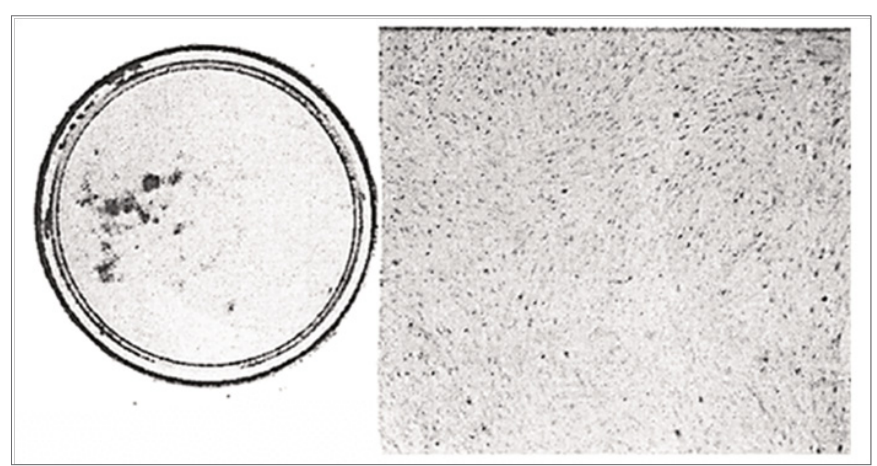

Figure 15 Effect of SA on inhibiting SV40-transformation of mouse cells with SA. C3 H mouse kidney cells $\left(10^{3}\right)$ were seeded on one plate in the presence of $35 \mu \mathrm{g} / \mathrm{ml}$ of SA and infected with SV40 virus (1 $\left.0^{6} \mathrm{PFU} / 0.2 \mathrm{ml}\right)$. Black spot are there, but no transformation observed. c. In the plate on the right side of the photograph, the cell contact inhibition is clearly shown after the addition of SA $(35 \mu \mathrm{g})$. The left side photo shows the aggregation of cells, which is clearly transformed (Figure 16).

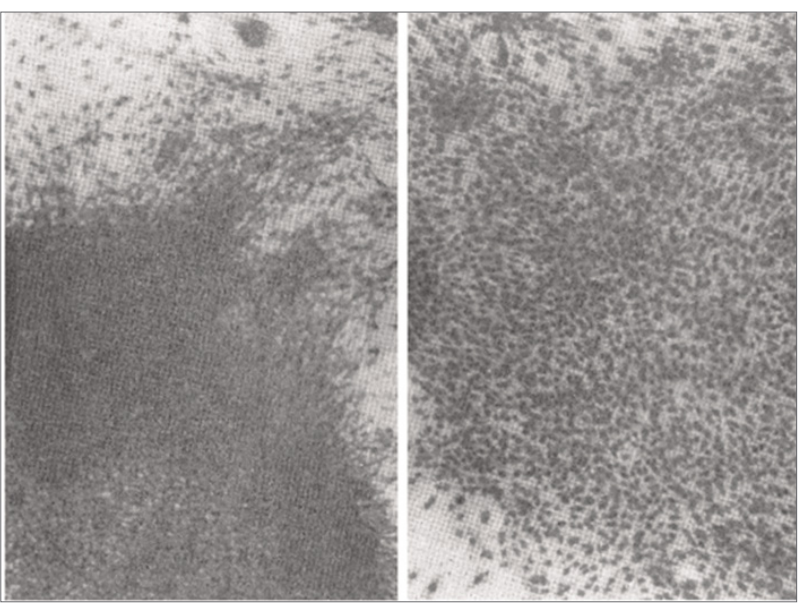

Figure 16 Microscopic observations of the black sites under high magnification. Mouse kidney cells $\left(10^{3}\right)$ were seeded in the absence (left side) and presence (right side) of SA $(35 \mu \mathrm{g} / \mathrm{ml})$. SV40 virus $\left(3.5 \times 10^{6} \mathrm{PFU}\right)$ was infected. They were grown up for 14 days. There is confirmatively cell to cell contact inhibition on the right side photograph in comparison with left side photograph which showed transformation and aggregation.

d. In this figure, $10^{3}$ mouse kidney cells are seeded on one plate and then SV40 virus $\left(10^{6} \mathrm{PFU} / 0.2 \mathrm{ml}\right)$ was absorbed. SA $(35 \mu \mathrm{g})$ was added according to the schedules A $\sim \mathrm{H}$ (Figure 17). We can visually observe in the following figure that transformed foci are observed in low $\mathrm{Ca}^{2+}$ medium (Figure 17). In the figure (Lower figure), black bar mark indicates the addition of SA. The data show that SA prevents SV40 virus transformation by reversing the transformation.

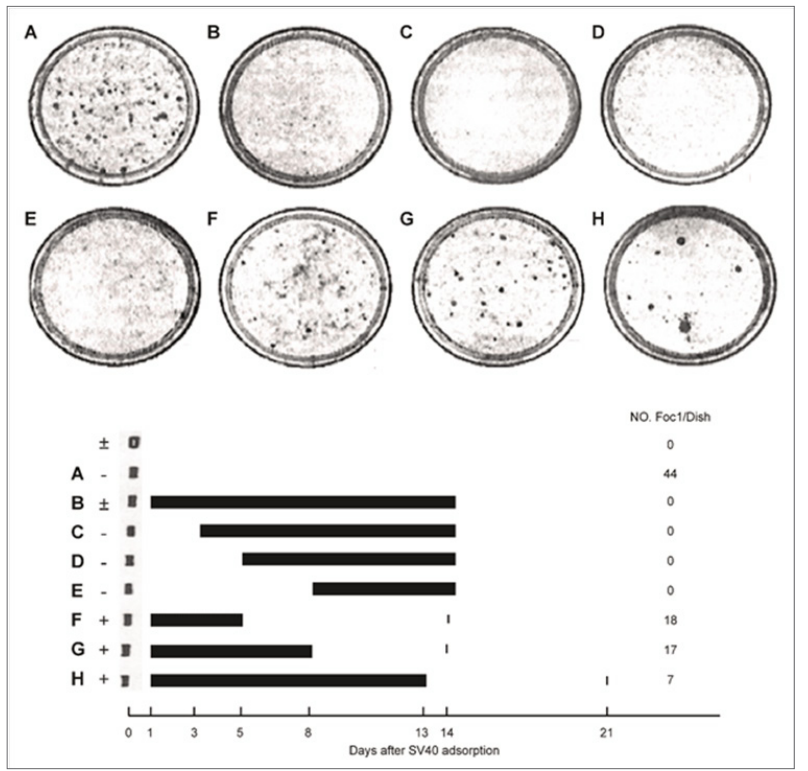

Figure 17 Inhibition of SV40 virus-transformation by SA. Mouse kidney cells $\left(10^{3}\right)$ were treated with SV40 virus $\left(10^{7} \mathrm{PFU} / 0.2 \mathrm{ml}\right)$ or Hanks' BSS in the presence (+) or absence (-). And $1.5 \times 10^{4}$ cells/ dish were seeded in the low calcium medium on day I. SA $(35 \mu \mathrm{g})$ was subsequently added as shown black bar. Foci were scored on day 4 or 21 . 
v. We utilized fluorescence antibody methods to determine whether SA can inhibit carcinogenesis via SV40 virus infection ${ }^{23}$ shown in the following (Figure 18). After CV1 cells were infected with the SV40 virus, the cell membrane produced $T$ antigen; however, the proliferation of transformed cells was stopped when SA was added beforehand. This image shows cells infected by the SV40 virus and viral DNA was incorporated into the cellular DNA, nevertheless, this experiment demonstrates that carcinogenesis was inhibited by SA at step 5 of proliferation (Figure 18). Fluorescent color was admitted when T-antigen was produced (Figure 19).

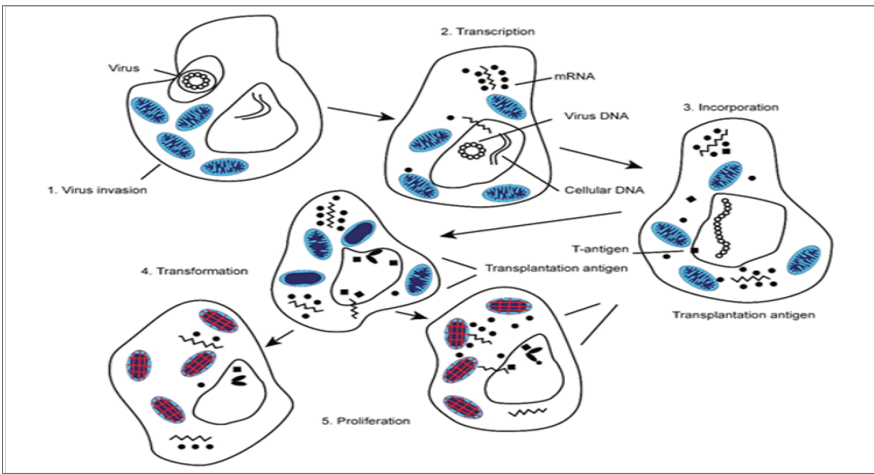

Figure $18 \mathrm{~T}$ antigen induced from SV40 virus was surveyed by indirect fluorescent antibody method.

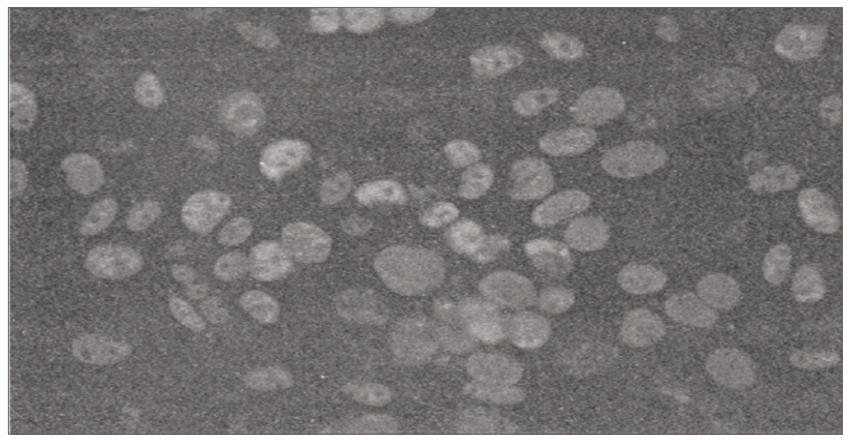

Figure 19 Fluorescent colors was admitted when T-antigen was produced When SV40 virus was infected on CVI cell and viral DNA is incorporated into nuclear DNA, T-antigen will be produced on the cell surface.

SV40 virus $\left(3.5 \times 10^{4} \mathrm{PFU}\right) 0.1 \mathrm{ml}$ was cultured on monolayer of $\mathrm{CVI}$ cell with $\mathrm{SA}(35 \mu \mathrm{g} / \mathrm{ml}) \quad 1.4 \mathrm{ml}$ of tissue culture solution was added. Day 5 and 10 , coverslip was washed with PBS and fixed with acetone for 10 minutes. AntiSV40T serum (cancer borne hamster serum I:20) $0.1 \mathrm{ml}$ was incubated for 25 minutes at $37^{\circ} \mathrm{C}$. After washing with PBS, $\square$ stained with anti-Hamster- $\gamma$-FITC (I:I5, $\square$ Sanko-Junyaku) and washed with PBS and $D_{2} W$ and enclosed with $90 \%$ glycerol.

vi. This graph shows that the growth curve of SV40 virus-transformed cancer cells was quantitatively inhibited by the addition of SA. Because SA inhibits damaged mitochondrial respiratory dysfunction, SA inhibits carcinogenesis before and after SV40 virus transformation (Figure 20).

vii. SA adjust lipid metabolism (Figure 21). These experiments of SA on lipid metabolism were carried out among 5 candidates. Because cancer patients usually show hyper-lipemia, SA will be working well because SA has adjusting functions on lipid metabolism. Up to now the effect of herbal medicine on cancer cell has suggested no correlation with gene abnormality of cancer cell at all.

3. The Warburg effect was misunderstood because it indicated that in normal cells; approximately $100 \%$ of the ATP is produced by oxidative phosphorylation, whereas in cancer cell approximately $100 \%$ of the ATP is produced by glycolysis. Although Reitzer LJ et al. ${ }^{24}$ reported that Hela cells cannot live without oxygen, the internal ATP levels were maintained by glutamine energy metabolism under aerobic conditions for up to 120 minutes. This finding indicates that aerobic glycolysis and mitochondrial ATP $\square$ production are necessary to maintain ATP, even if the cancer cells survive $^{24}$ (Figure 22). Thus, the survival of cancer cells may be inhibited because the necessary internal ATP energy cannot be produced, which is perhaps why cancer cells stop proliferating and transforming when SA is administered.

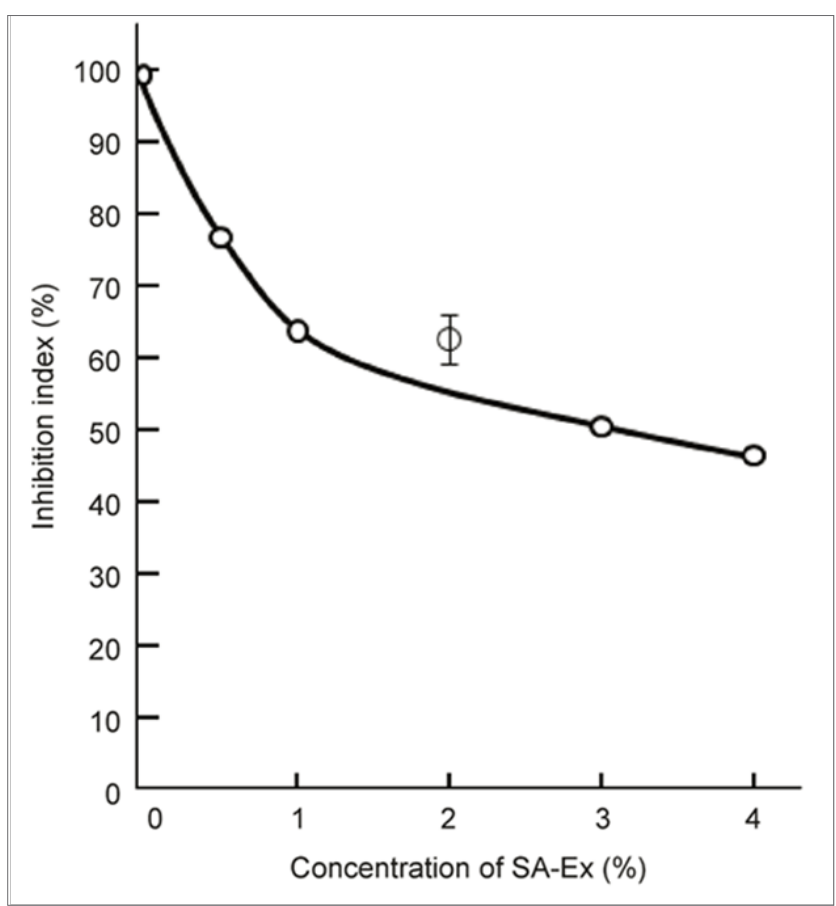

Figure 20 Dose response relationship for the action of SA-Ex on SV40transformed mouse kidney cells.

$3 \times 10^{3}$ cells/ dish, sub-cultured from a SV40 transformed colony in the low $\mathrm{Ca}$ ${ }^{2+}$ medium, were seeded and treated with SA-Ex which was the combination of SA and apple and cucumber juice (50/50), on day 3. Colonies were counted on day 10.The number of colonies without SA-Ex was 190.

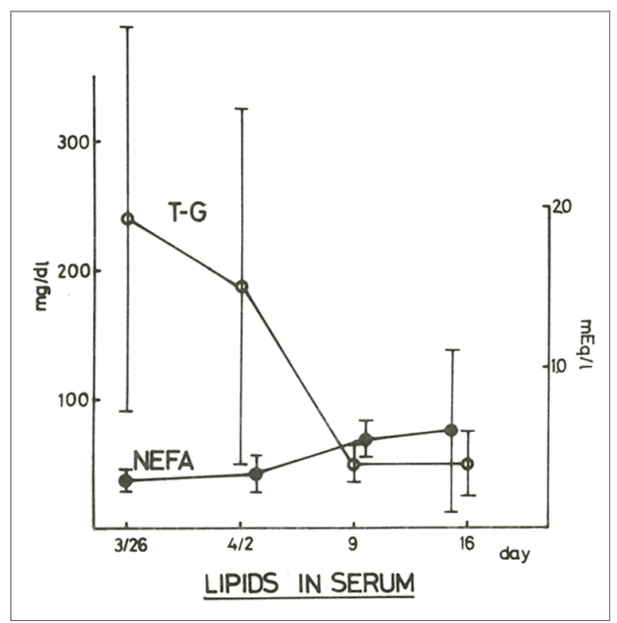

Figure 2I We have checked the lipid metabolism utilizing SA (I.6g/ day) on 5 residents because tumor bearing patients showed hyper-lipemia. NEFA increase and tri-glyceride decreased by SA intake. 


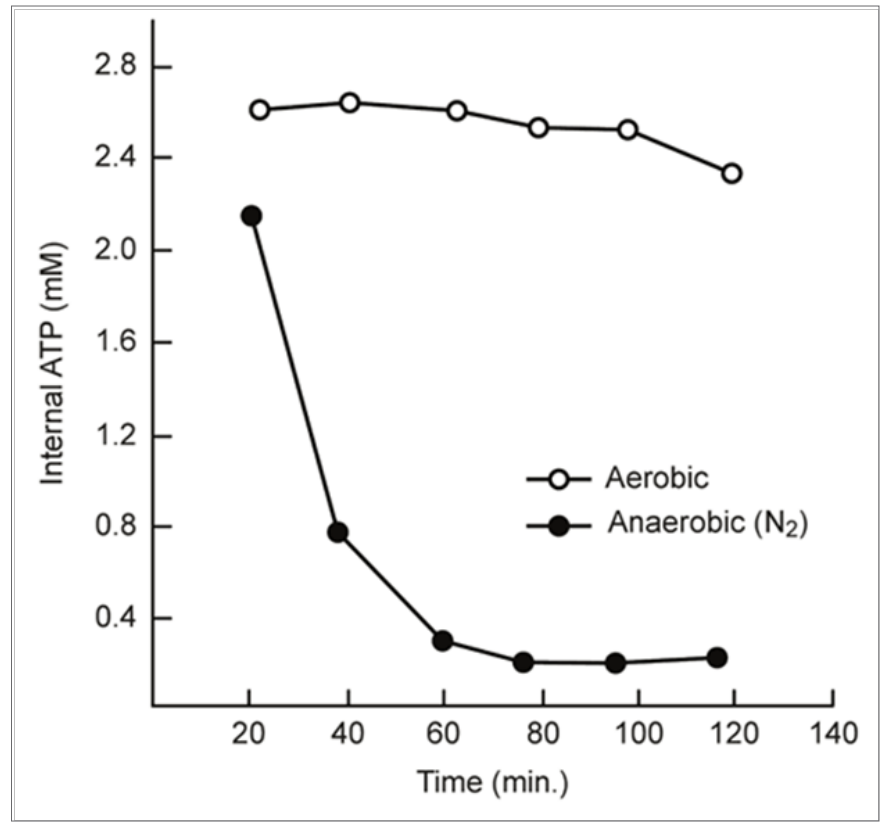

Figure 22 Reitzer et al. ${ }^{42}$ has demonstrated that the concentration of ATP in Hela cells incubated in the absence of sugar with or without oxygen. Cells were pregrown in Minimum Essential Medium Joklik, 5\% nondialyzed fetal calf serum spinner cultures, which support exponential growth to $10^{6} \mathrm{cells} / \mathrm{ml}$. At $3 \times 10^{5} \mathrm{cells} / \mathrm{ml}, 200 \mathrm{ml}$ was centrifuged at $1500 \mathrm{~g}$ for $15 \mathrm{~min}$ at room temperature and immediately re-suspended in $10 \mathrm{ml}$ of Minimum Essential Medium Jolik containing 20mM 4-(2-hydroxyethyl)-L-piperazine-ethane-sulfonic acid, $\mathrm{pH} 7$, without serum or glucose. The medium used for the anaerobic incubation had been deoxygenated by bubbling $100 \% \mathrm{~N}_{2}$ though it for at least $10 \mathrm{~min}$. the cells were re-suspended gently to avoid oxygenating the medium and the gassing continued above the medium during the incubation. The aerobic culture was exposed to the atmosphere. The flasks were shaken rapidly in a water bath at $37^{\circ} \mathrm{C}$. At the indicted times, $1.5 \mathrm{ml}$ of culture was mixed with $0.25 \mathrm{ml}$ of $2.4 \mathrm{~N}$ $\mathrm{HClO}_{4}$ with $8 \mathrm{mM}$ EDTA at $0^{\circ} \mathrm{C}$., and centrifuged at $12,006 \mathrm{~g}$ for $20 \mathrm{~min}$. The supernatant was neutralized with $\mathrm{KOH}$, using the phenol red indictor present in the medium, and after removing potassium perchlorate by centrifugation, ATP was measured as described. ${ }^{42}$

4. However, in reality, normal cells produce $10 \%$ of their ATP via glycolysis and $90 \%$ of their ATP via oxidative phosphorylation and these proportions may be related to the proportions of mitochondrial DNA in mitochondria $(10 \%)$ and $90 \%$ of mitochondrial DNA left in the nucleus. In contrast, cancer cells can produce $60 \%$ of their ATP via glycolysis and $40 \%$ of their ATP via oxidative phosphorylation, which is indicated in the bellow's figure. Oxidative phosphorylation decreased to $40 \%$ based on the percentage of mitochondria respiratory function in cancer cells exhibiting dysfunctional cell changes into cancerous immortal cells. ${ }^{25} \mathrm{I}$ believe that normal cells transform into immortal cells because of the dominant form of energy production system revert from oxidative phosphorylation to the bacterial glycolysis, which is the original bacterial energy production. I think that changing of energy production system, consequently, cell division system is changed from eukaryotic type to bacterial type (Figure 23). Based on these considerations, SA was found to inhibit the remaining aerobic respiration of oxidative phosphorylation (Krebs cycle) in cancer cells. We must suggest the biological puzzle why $90 \%$ of mitochondrial DNA inserted into nuclear DNA and 10\% of mitochondrial DNA locate in mitochondria. Thereby, decreasing
Krebs cycle to less than $40 \%$ and it also would decrease excessive inhibition of oxidative phosphorylation to less than $40 \%$. Thus, the survival of cancer cells may be inhibited because the necessary internal ATP energy cannot be produced, which is perhaps why cancer cells stop proliferating and transforming when SA is administered. By the way, Sesaki Hiromi et al. ${ }^{19}$ has reported that $\square$ mitochondrial division is requisite to RASinduced transformation and targeted by oncogenic MARK pathway inhibitors. ${ }^{19}$ This mitochondrial reversible change may be correlated with the mitochondrial change above mentioned (Figure 24). As to the defective immune-surveillance of cancer patients, PD-1 and PD-L1, immune-checkpoint inhibition phenomenon was reported from molecular biology. Another biochemical cause of defective immune-surveillance will be demonstrated in the next chapter.

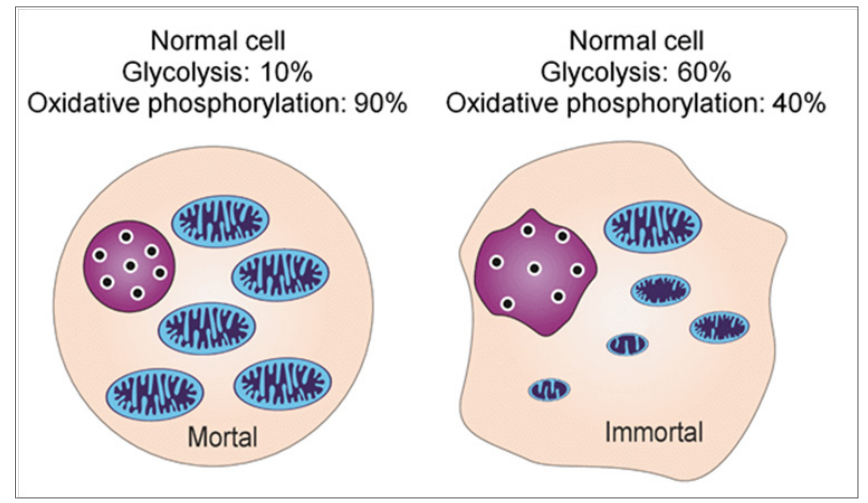

Figure 23 Figurelistic difference of mitochondria between normal cell and cancer cell. The difference between normal cell and cancer cell may be the difference between mitotic cell division depends upon the oxidative respiration phosphorylation and bacterial cell division depends upon glycolic fermentation.

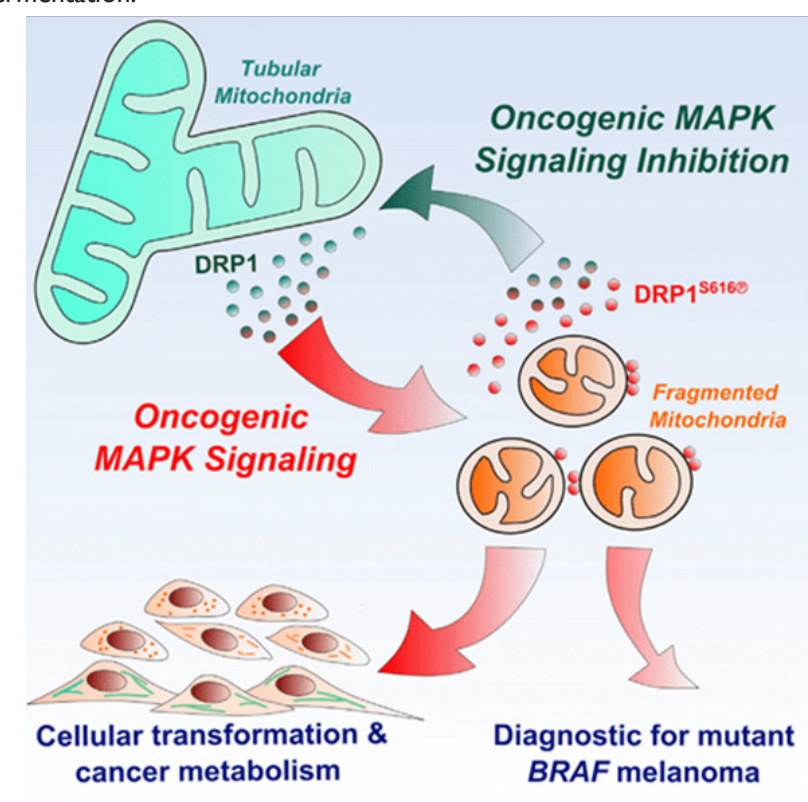

Figure 24 Tubular mitochondrion was changed to fragmented mitochondria by oncogene signaling and fragmented mitochondria were changed to matured mitochondria by oncogenic signaling inhibition.

Sesaki $\mathrm{H}$ et al. $^{15}$ report was cited..$^{18}$ 
5. In the next experiment, we attempted to solve the issue of defective immune-surveillance in cancer patients which was investigated via an experiment utilizing adoptive immune lymphocyte's therapy. ${ }^{25}$ We observed the immune activity after the intravenous dripping infusion of $1 \sim 2 \times 10^{8} / \mathrm{ml}$ of lymphocytes in advanced cancer patients according to schedule 1 as follows (Figure 25). Feasible increase in immune activity were not observed compared with that observed in early cancer patients, which indicates that immune activity function is suppressed in advanced cancer patients. This phenomenon is the so-called defective immune-surveillance. Thus we performed schedule 2 on 17 volunteer cancer patients (Figure 26). The effectiveness of the lymphocyte adoptive lymphocyte's therapy combined with fasting therapy was increased compared with that of the adoptive lymphocyte's therapy alone (Figure $27)$. With schedule 2 , the immune activity( $\mathrm{T}$ cell number (59-> 70), stimulation index(SI) (33->56) and NK activity ( 53->70)) were elevated compared with that of schedule 1 in advanced cancer patients, because of the elevation of cyclic AMP in the serum after fasting therapy, which is shown in the next figure. Therefore, I believe that the phenomenon of decreased serum concentrations of cyclic AMP is the biochemical cause underlying the defective immune-surveillance phenomenon in cancer patient from macroscopic study. Fasting treatment elevate cyclic AMP concentrations in the serum (Figure 28). These experiments of adoptive immune-lymphocyte's therapy shows that lowering of cyclic AMP in the serum in cancer patients lead to the biochemical cause of defective immune-surveillance of cancer patients. From now, I will report the direct effect of cyclic AMP itself on cancer cells.

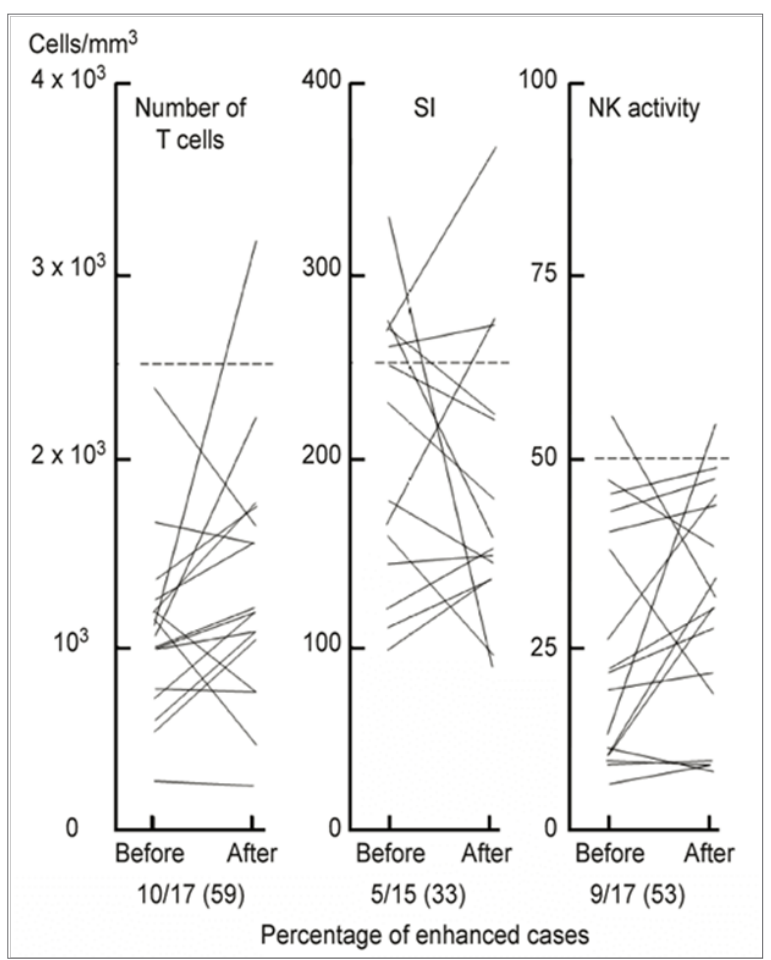

Figure 25 Adoptive lymphocytes therapy on advanced cancer patients Lymphocytes was gotten from $100 \mathrm{ml}$ of donor's blood by centrifugation method utilizing Lymphoprep $\AA$ and suspended in physiological serine and made suspension of $1 \sim 2 \times 10^{8} / \mathrm{ml} \mathrm{SI}$ is stimulation index by PHA. So as to release cancer antigen from cancer tissue, we have manipulated cancer patients utilizing the combination of vitamin $A\left(5 \times 10^{4} \mathrm{U}\right)$ and sauna bathing at $56^{\circ} \mathrm{C}$. For 20 minutes. Adoptive lymphocytes were infused after $24 \sim 30$ hours inducing cancer antigen treatment.
6. Colorado University group, $\mathrm{AW} \mathrm{Hsie}^{26}$ demonstrated that the addition of $1 \mathrm{mM}$ of cyclic AMP led to the re-differentiation of ovarian cancer cells into normal fibroblasts within 5 hours. ${ }^{26}$ This cellular morphological change could be induced by the directly cyclic AMP influencing on damaged mitochondria or microtubules (Figure 29) in a short time. This differentiation phenomenon may have no correlation with gene abnormality of cancer cells. Oboshi et al. reported that glioma neuroblasts (NB1 cells) could be re-differentiated into normal nerve cells by the addition of $1 \mathrm{mM}$ of cyclic AMP after 1 month. Thus, cyclic AMP has shown effective differentiation-promoting abilities. Cyclic AMP not only has differentiation-promoting abilities in cancer cells, but also plays a key role unlocking the defective immunesurveillance phenomenon in cancer patients. ${ }^{25}$ Otherwise, Sato ${ }^{27}$ and Stanley et al. have reported that Friend leukemia cells could be re-differentiated into erythroblasts by the addition of $1.5 \%$ dimethyl-sulfoxide. These re-differentiation experiments show that carcinogenesis has no correlation with gene abnormality of cancer cells.

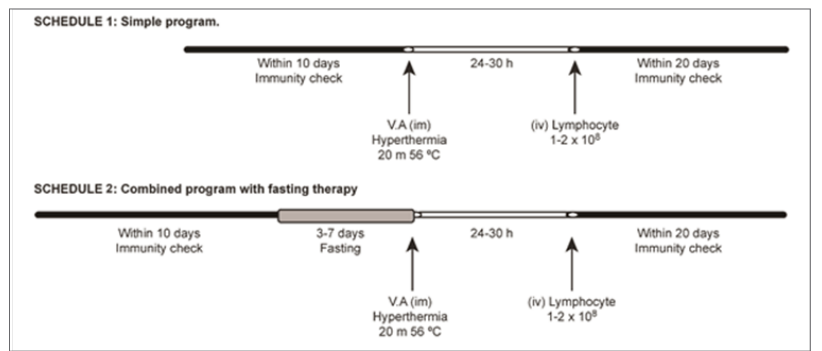

Figure 26 Lymphocyte adoptive immunotherapy treatment's schedules. So as to release cancer antigen from cancer tissue, we have manipulated cancer patients utilizing the combination of vitamin $A$ (retinoic acid: $5 \times 10^{4} \mathrm{U}$ ) and sauna bathing at $56^{\circ} \mathrm{C}$ for 20 minutes. Adoptive lymphocytes were infused after 24 30hours inducing cancer antigen treatment.

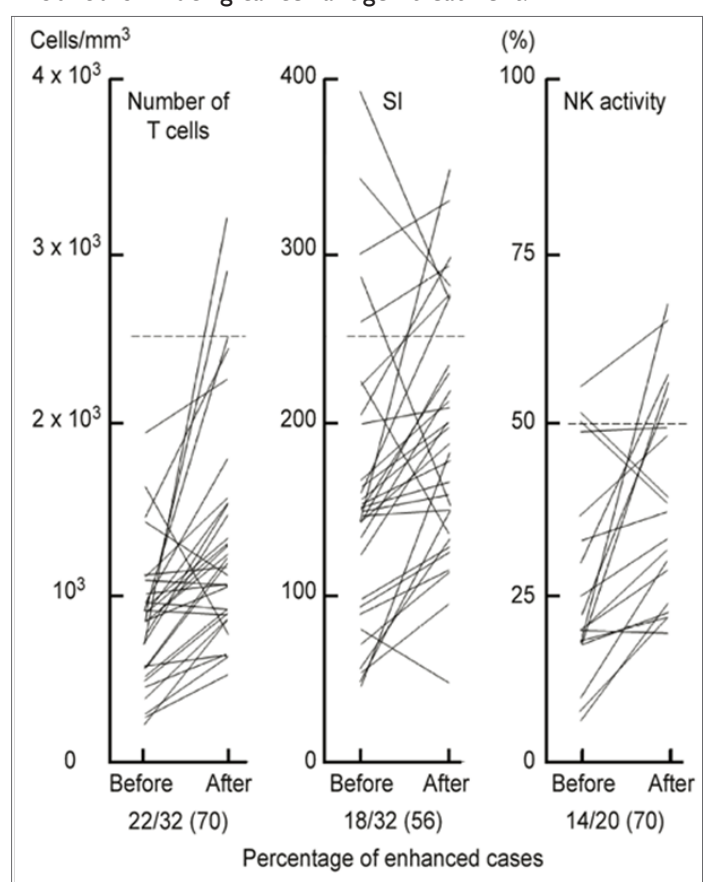

Figure 27 These experiments were carried out by the schedule of 2.Adoptive lymphocytes $\left(1 \sim 2 \times 10^{8} \mathrm{ml}\right)$ therapy, so as to release cancer antigen from cancer tissue, we have manipulated cancer patients utilizing the combination of vitamin $A$ (retinoic acid: $5 \times 10^{4} \mathrm{U}$ ) and sauna bathing at $56^{\circ} \mathrm{C}$ for $\square 20$ minutes. Adoptive lymphocytes were infused after 24 30 hours inducing cancer antigen treatment. 


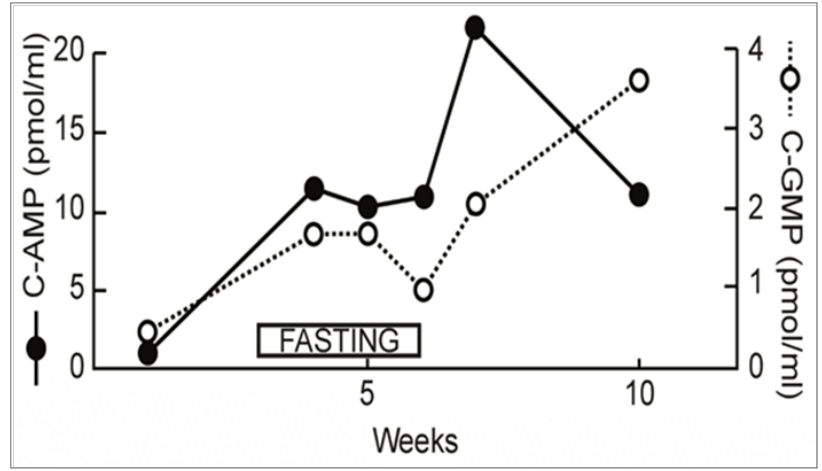

Figure 28 Fasting treatment elevates the cyclic AMP concentrations in the serum. Application of fasting induces increasing of cyclic AMP and followed cyclic GMP.

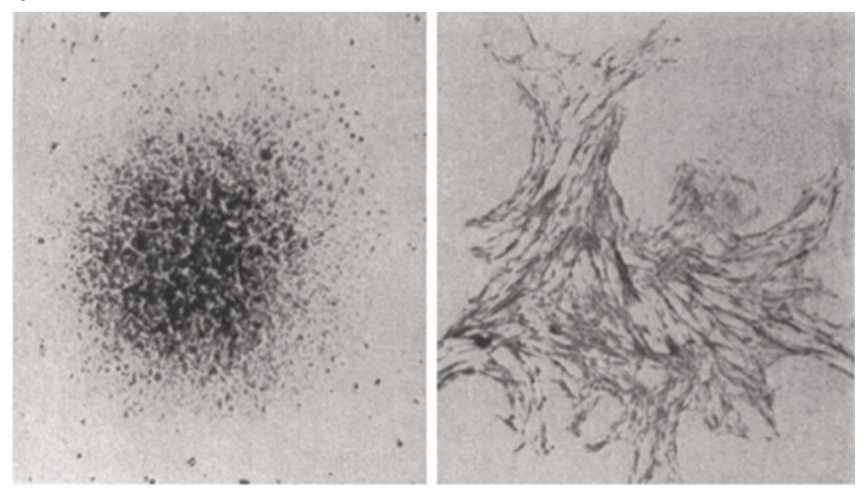

Figure 29 Colorado university group ${ }^{25}$ has demonstrated the high differentiation promoting ability of cyclic AMP on ovarium cancer cells. Within 5 hours after the addition of I mM of cyclic AMP, ovarium cancer cell was re-differentiated into normal fibroblast. As $\mathrm{Dr} \mathrm{H} \mathrm{Hie}^{25}$ has said that this morphological chaging may be induced from microtubules, but I think this changing may be induced from mitochondrial effect.

7. Professor Shigeru Arichi ${ }^{28}$ reported that the addition of Panax Ginseng saponins $(20 \mu \mathrm{g})$ leads to the re-differentiation of Morris hepatoma cells into normal liver cells after 2 months (Figure 30). ${ }^{28}$ Hepatoma cells could re-differentiate into normal liver cells with the use of Panax ginseng saponins $(20 \mu \mathrm{g})$ after 2 months. On this experiment, electron microscope photographs clearly verified that shrunken mitochondria were re-differentiated into normal matured mitochondria as shown below (Figure 31). Segregated smaller mitochondria reverted to normal matured large mitochondria after the addition of Panax ginseng saponins $(20 \mu \mathrm{g})$ in the next Figure 31. Panax ginseng experiment also suggests that there is no correlation with re-differentiation of Morris hepatoma cell and gene abnormality of cancer cells.

8. It is important to highlight that the following formula is incorrect: Incorrect cancer tissue $=$ cancer cell $\mathrm{x}(\mathrm{n})$ and cancer cells grown up endlessly. Correct cancer tissue is composed of 3 components: onco-fetal antigen ( $\square-T M)$, onco-placental antigen (a-TM) and cancer vessels (g-TM) likewise, the fetus is similarly composed of the fetus itself, the placenta and the chorion ${ }^{29}$ (Figure 32). Recently anti-oncogene was showed to be essential for the evolution of multi-cellularity ${ }^{30}$ by Japanese and American researchers. In the case of induced pluripotent stem (iPS) cell formation, 3 genes and 1 c-myc gene, total of 4 genes are necessary. So, in a reprogramming procedure, Yamanaka S, the Novel Prizer utilized c-myc oncogene as one of Yamanaka factors. ${ }^{31}$ Thus, reprogramming procedure is a kind of procedure of carcinogenesis. When carcinogenesis occurs, the number of mitochondria decrease in number and the shape of mitochondria diminish and this process resembles what occurs in sperm cells because sperm usually have few mitochondria. In other words, the mitochondria dedifferentiate, that is, which represents process of a developmental differentiation.

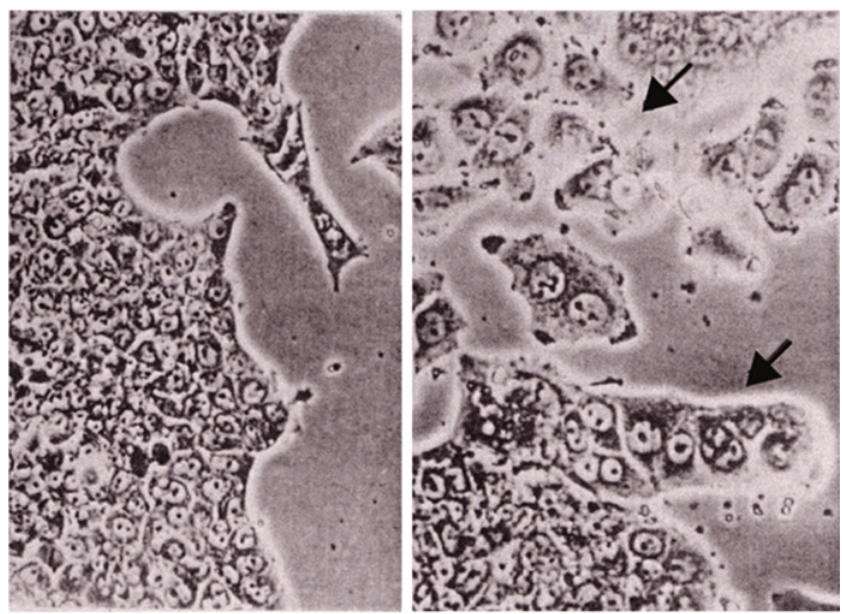

Figure 30 Kinki University group ${ }^{27}$ showed that Morris Hepatoma cell could be re-differentiated into normal liver cell by the addition of Panax ginseng extract( $20 \mu \mathrm{g})$ after 2 months. Contact inhibition is appeared after 2 months later.

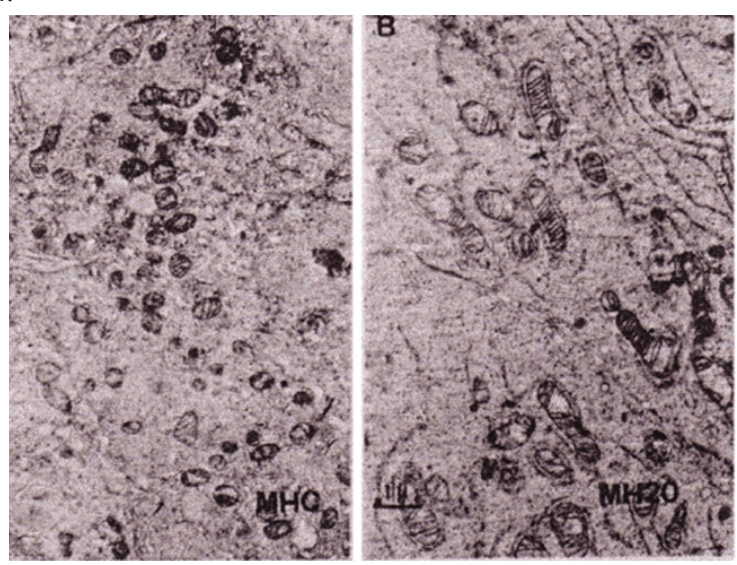

Figure 3IUnder electron microscope, photograph shows that shrunken and segregated mitochondria have become to normal large matured mitochondria

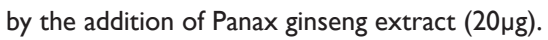

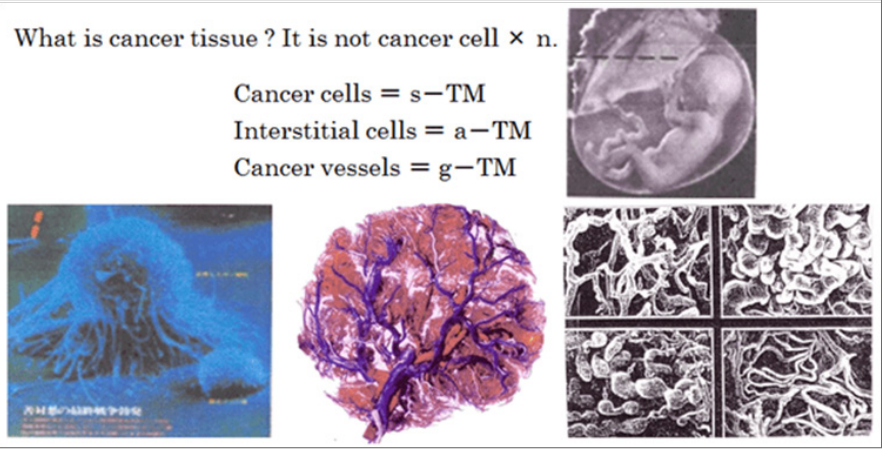

Figure 32 What is cancer? 


\section{Second project}

Thomas Seyfried reported that replacing of damaged mitochondria the normal $\square$ mitochondria produced sufficient energy via respiration and restored the differentiation state. Therefore, we exploited a new treatment for restoring damaged mitochondria so as to restore damaged mitochondria into normal mitochondria by the following 6 item's combination of vitamin A, high dose of vitamin C, Sorcoseryl, Herbal medicine (Sun Advance), cyclic AMP, and HSP induced from hyperthermia for the following reasons.

a) Vitamin $\mathrm{A}\left(5 \times 10^{4}\right.$ units $)$ injection(ic) were administered because the serum of cancer patients generally display low concentrations of vitamin A and a shortage of vitamin A- binding protein in cancer patient's serum. ${ }^{32-34}$ Furthermore, vitamin A has the ability to differentiate juvenile cells to differentiated cell.

b) High dose of vitamin C (30-70 g) were administered to increase the hydrogen peroxide in cancer cells ${ }^{35-36}$ and suppress the growth of cancer vessels.

c) Solcoseryl $(2 \mathrm{ml} / 1 \mathrm{~A})$ extracted from the hemolyzed blood (SS-094) of young cattle ${ }^{37}$ was administered because it promotes mitochondrial function and wound healing and corrects the glycolysis in hypoxic microenvironments (Figure 33).

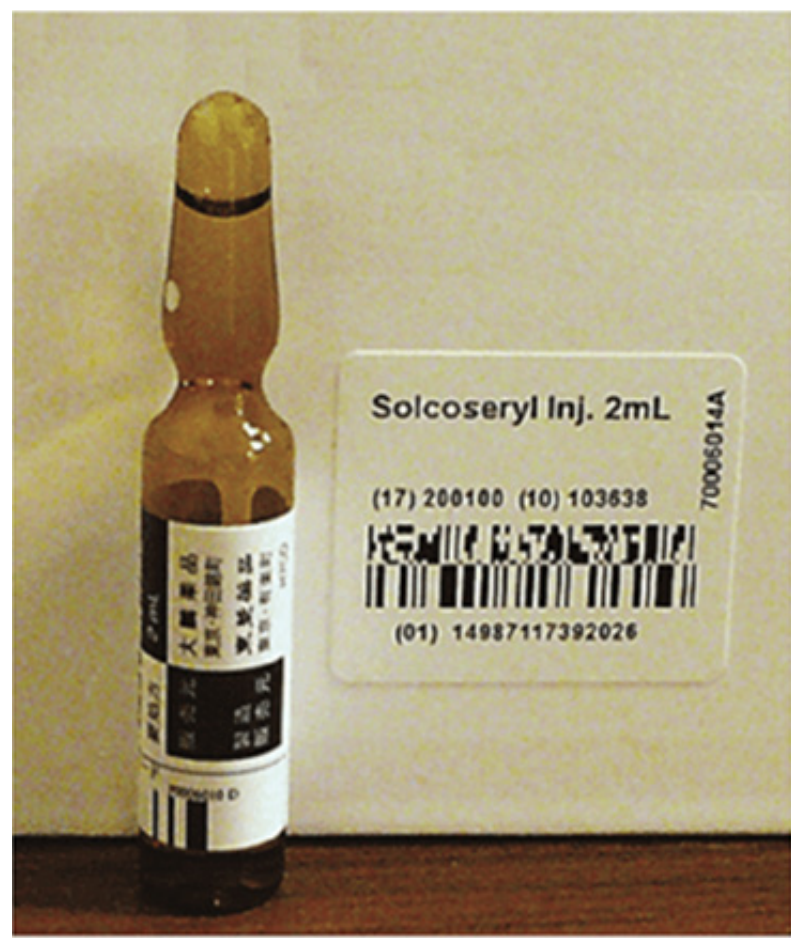

Figure 33 Solcoseryl $®$ is forgotten medicine and is important mitochondrial medicine which is promoting mitochondria function and which was manufactured by Taiho Pharmaceutical Company.

d) A combination of an intravenous dripping infusion of cyclic AMP( bucladesine sodium 300mg/1A) and aminophylline( $125 \mathrm{mg}$ ), which is blocking agent of cyclic phosphodiesterase to correct the defective immune-surveillance of cancer patients' serum ${ }^{29}$ by maintaining appropriate concentrations of cyclic AMP in the serum. Cyclic AMP works with calcium as a second hormonal messenger because a low calcium medium is conducive in carcinogenesis. e) $\mathrm{SA}^{21,22}$ was prescribed to prevent carcinogenesis, prevent onco-virus transformation and exclude immunosuppressive substances from the body $\square$ because of inhibiting the respiration of cancer cells.

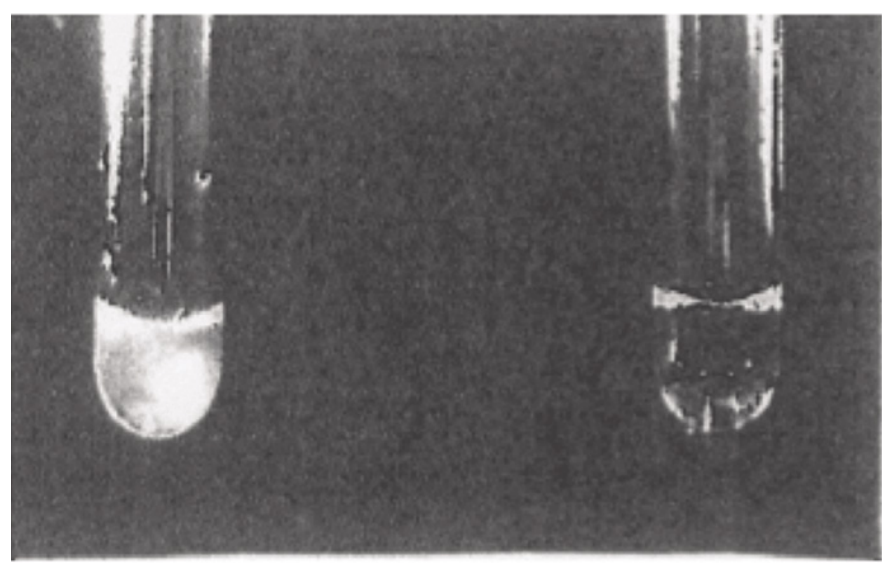

Figure 34 Boiled chicken egg protein becomes aggregated and turns white after hyperthermia treatment at $70^{\circ} \mathrm{C}$ for 10 minutes (left tube). However when bacterial HSP was added to chicken egg protein beforehand, egg protein don't aggregate.

f) When these treatments were not sufficient, hyperthermia treatment was administered to produce ample HSP molecules in the lymphocytes and cancer cells. Hyperthermia treatment is effective for cancer neoplasms because of the structure of cancer blood vessels. ${ }^{38-42}$ We must importantly remember that natural spontaneous regression of cancer has been observed after long-lasting episodes of fever. As shown in the next image, boiled chicken egg protein becomes aggregated and turns white after treatment at $70^{\circ} \mathrm{C}$ for 10 minutes, and it changed into white (left tube) (Figure 34). However, bacterial HSP was added to chicken egg protein beforehand, which was boiled again in the same manner, and no aggregation is shown on the right side. We can confirm that the chicken egg protein aggregation was protected by the addition of bacterial HSP. Anyway, HSP is just a cradle of protein because its functions are related to the management, degradation, maintenance and reproduction of the proteins. HSP is shown in the electron microscopic image below figures ${ }^{42}$ (Figure 35). HSP is important as a shaperone when mitochondrial produced proteins in the nucleus are delivered to mitochondria replication. Heat treatment induces an increase in intracellular cyclic AMP concentrations in cancer cells ${ }^{43,44}$ and this HSP has also been reported to function in the differentiation and evolution of cells. ${ }^{45}$

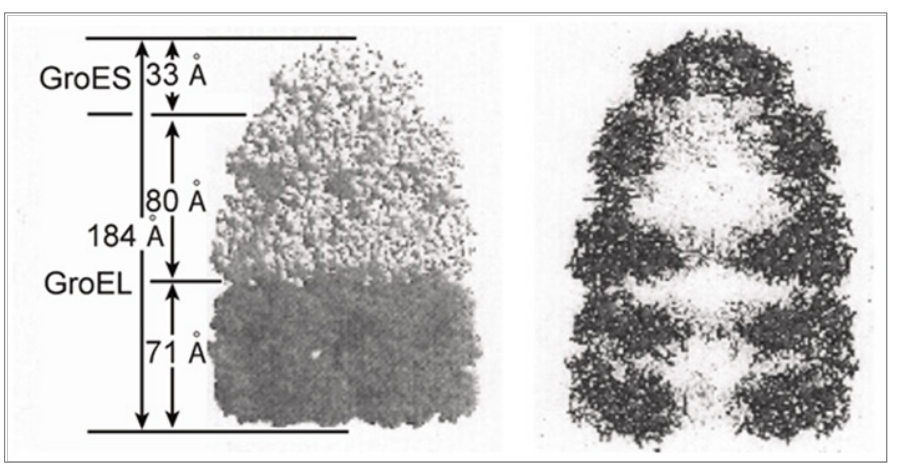

Figure 35 HSP is just a cradle shape of protein under electron microscope. ${ }^{41}$ 
g) Therefore, the 6 items included in the treatment have been summarized. This treatment is referred to as cancer re-differentiation inducing treatment.

\section{First case}

We applied this treatment on a recurred patient (48 years old male) who suffered from the recurrence of Leiomyosarcoma as pathological diagnosis on the upper right hand. After surgical resection (27, May, 2015), the sarcoma metastasized to the lung in September, 2015. Chemotherapy was performed with doxorubisin (126mg), but it did not disappear by December, 2015. Therefore, the patient presented at my hospital, and he subsequently received the cancer re-differentiation-inducing treatment (Figure 36). Left photograph shows a CT at September, 2015, center and right photograph show the CT at January, 2016. As shown in CT image, metastases have clearly disappeared after January 2016 (Table 1). The patient's initial risk assessment according to the TMCA was classified as tumor stage $\mathrm{V}\left(=\mathrm{G}_{2}\right)$, whereas, in July 2017, the TMCA risk assessment was classified as TS (III). There is no relapse of recurrence for 2 years after he received re-differentiation inducing treatment.

Table I Proceeding of metastasized Leiomyosarcoma patient (48 years old male) in the lung who was followed by various tumor marker

\begin{tabular}{|c|c|c|c|c|c|c|}
\hline Time course & 14.Jan.2016 & 14.Jan.2016 & 18.Feb.2016 & 17.Mar.2016 & 19.Apr.2016 & 13.Jun.2016 \\
\hline Ferritin (FT) & 489 & 337 & 186 & 225 & 195 & 208 \\
\hline Serum iron(Fe) & 75 & 67 & 46 & 78 & 71 & 85 \\
\hline $\mathrm{FT} / \mathrm{Fe}$ & 6.5 & 5 & 4 & 2.8 & 2.7 & 2.4 \\
\hline Thymidine & 59.1 & 5.9 & 2.1 & 3.6 & 3.1 & 4.5 \\
\hline Kinase (TK) $\alpha$ I-globulin & 3 & 2.6 & 2.6 & 2.4 & 2.4 & 2.4 \\
\hline Albumin & 60.7 & 60.4 & 62.3 & 60.7 & 60.2 & 61.1 \\
\hline Risk assessment & $\mathrm{TS}(\mathrm{V})(\mathrm{G} 2)$ & $\mathrm{TS}(\mathrm{IV})$ & $\mathrm{TS}(\mathrm{IV})$ & $\mathrm{TS}(\mathrm{III})$ & $\mathrm{TS}(\mathrm{III})$ & $\mathrm{TS}(\mathrm{III})$ \\
\hline CT exam. & Meta $(+)$ & $(-)$ & & & $(-)$ & \\
\hline
\end{tabular}

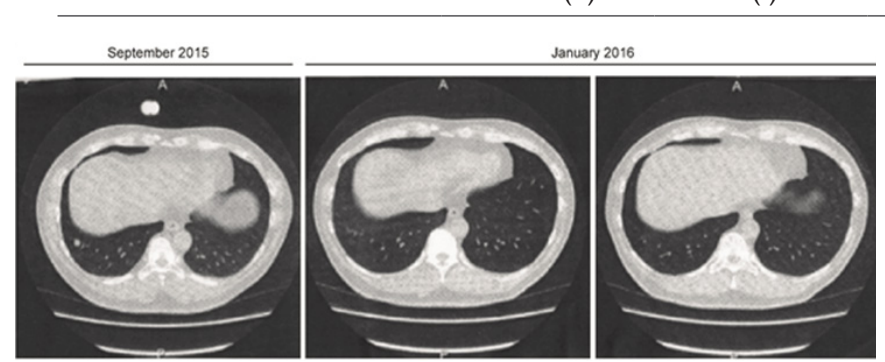

Figure 36 CT finding of case I after resection of sarcoma on left upper-hand, sarcoma was metastasized to the lung. But metastasis was disappeared one month after the re-differentiation inducing treatment.

\section{Second case}

The second case study shows that 30 years old female woman suffered from undifferentiated ovarium cancer and her pathological diagnosis was undifferentiated germinoma. She received resection of the ovarium twice. After resection, she underwent chemotherapy 4 times. Subsequently she presented at my hospital and underwent tumor marker-inducing examination utilizing a combination of vitamin A and hyperthermia. ${ }^{46,47}$ The following data were recorded: CEA: $2.2 \mathrm{ng}$, $\triangle \mathrm{CEA}$ which means the width of changing data during 48hours; $1.0 \mu \mathrm{g})$, Ferritin(FT);160 $\mu \mathrm{g}(\Delta \mathrm{FT}: 40 \mu \mathrm{g}), \mathrm{FT} / \mathrm{Fe}=2.2, \Delta \mathrm{FT} / \mathrm{Fe}=0.6$, LDH: $294(\Delta \mathrm{LDH}=41 \mathrm{U})$, Ribonuclease (202 U), $\alpha 1$-golbulin:3.5\%, Albumin (64\%), $\mathrm{T}$ cell number (1468), stimulation index $\square(173)$, and NK cell activity (17.8\%) I have diagnosed her condition as TS (V): gram level cancer: G2 (clinical level): cancer stage II according to cancer risk assessment method by TMCA which was reported in cancer. ${ }^{29}$ Then, she underwent a PET examination, which revealed a right side Virchow lymph-node metastasis. The patient subsequently received SA by oral intake and detoxifying refreshment treatment and dietary energy restriction for 6 months and the clinical findings indicated that she had improved into normal range showed below Table 2. The patient was followed for 18 years later and her cancer has not recurred. Patient's TMCA data are currently as follows: Thymidine kinase: 7.7, $\alpha 1$-globulin fraction (2.6\%), Albumin (61.1\%), LDH (238). In addition, her present risk assessment was classified into TS (III). In her case, there is no relapse at all for 18 years. We applied this type of treatment for 30 cancer patients and success was observed in $70 \%$ among these patients, most of them are no recurrence.

Table 2 The proceeding of undifferentiated ovarium cancer (30 years old female)

\begin{tabular}{lllllll}
\hline Date & Oct.(1999) & July(2000) & Jan.(200I) & Feb.(2002) & Jan.(2005) & July(20I5) \\
\hline RNase & 202U & 147 & $\mathrm{III}$ & 99 & 99 & - \\
Thymidine kinase & - & - & - & - & - & 7.7 \\
Albumin & $64 \%$ & 67.4 & $65 . \mathrm{I}$ & 65.2 & 62.9 & $61 . \mathrm{I}$ \\
$\alpha$ I-globulin & $3.50 \%$ & 2.9 & 3 & 2.9 & 2.9 & 2.6 \\
NK activity & $\mathrm{I} .80 \%$ & 24 & - & 66 & - & - \\
Risk assessment & $\mathrm{TS}(\mathrm{V})(\mathrm{G} 2)$ & $\mathrm{TS}(\mathrm{V})(\mathrm{GI})$ & $\mathrm{TS}(\mathrm{IV})$ & $\mathrm{TS}(\mathrm{IV})$ & $\mathrm{TS}(\mathrm{IV})$ & $\mathrm{TS}(\mathrm{II})$ \\
\hline
\end{tabular}




\section{Results}

I presented the results of 2 projects. The first project utilized $\mathrm{SA}$, which is a specific herbal medicine, which selectively inhibit the oxygen respiration of cancer cells at tissue culture level and animal experiment level. The findings indicated that most of the hallmarks of cancer were inhibited by SA, thus, this treatment is feasible for use. These data may demonstrate that mitochondrial respiratory dysfunction is the underlying entity in carcinogenesis and no correlation of primary DNA abnormality on carcinogenesis. The second project showed that the potential applicability of a redifferentiation-inducing treatment for damaged mitochondria, and the success of cancer re-differentiation inducing treatment showed that mitochondrial respiratory dysfunction would be the factor underlying of carcinogenesis. Cancer is not only a mitochondrial respiratory disease but also a developmental disease because mitochondria are deeply connected to cell differentiation. Thus, the transformation of cancer cells to immortal cells is a change on the sovereignty in the form of respiration from a higher energy production system (mitochondrial oxygen respiration) to an older type of bacterial fermentation system. Therefore, I have demonstrated that cancer is a reversible disease and not immortal disease caused by gene abnormalities, and it can be treated by restoring the protracted mitochondrial dysfunction via the 2 treatments described herein. Moreover, TMCA should be applied during integrative medical evaluations. ${ }^{29}$

\section{Discussion}

There are a great discrepancy between microscopic study and macroscopic study as yet. We have researched frontally on this problem. Many carcinogenic research of herbal medicine suggested indirectly that carcinogenesis induced ghost like change of mitochondria up to now, but my research of herbal medicine (SA) inversely showed for the first time that the inhibition of mitochondria degradation leads to the inhibition of carcinogenesis on the Thomas Seyfried's ${ }^{5}$ Figure 2. We have reported that core reason of carcinogenesis is depended upon the ghost like change or degradation and segregation of mitochondria according to Koch's rule. Sesaki Hiromi et al. ${ }^{19}$ proved that matured mitochondria changed to fragmented mitochondria by the oncogenic MAPK signaling and showed cancer metabolism, on the other hand, oncogenic MAPK signaling inhibition changed from fragmented mitochondria to matured mitochondria. Furthermore, Japanese and American researcher's group showed that anti-oncogene works for the evolution of multicellularity. On the other hand, the destruction of oxygen respiration $\square$ system in mitochondria should be considered an underlying cause for carcinogenesis because dedifferentiation produced reverting changes in the mitochondria shape and cristae, looking like procedure of reprograming because the Novel Prizer, Yamanaka Shinya of induced pluripotent stem (iPS) cell formation requires 3 gene and $1 \mathrm{c}-\mathrm{myc}$ gene and this c-myc is onco-gene which is requisite as Yamanaka factors. ${ }^{31}$

Fundamentally, energy production system is infrastructure of cellular life. So infrastructure of energy production system changed from high energy eukaryotic energy system to bacterial low energy system is more important reason of changing of cellular division system than genetic changing. As the molecular biologist explained that apoptosis become difficult after cytochrome $\mathrm{C}$ and calcium leaked out from mitochondria, nevertheless, this phenomenon has a possibility of secondary event from Sesaki Hiromi et al..$^{19}$ report and from my data. As we could not directly proved that herbal medicine (SA) let change morphological evidence of mitochondria, but herbal medicine SA has strong effect on lipid metabolism and because mitochondria is mainly composed of cardiolipin which paved the inner mitochondria membrane of cancer cell ${ }^{48}$ From immunological standpoint, the relationship between PD-1 and PD-L1 are intimately correlated with mitochondria function. Honjo Tasuku et al. ${ }^{49}$ reported that there is intimate correlation with mitochondria function and PD-1 receptor. ${ }^{49} \mathrm{PD}-1$ blockade shows that immune activity has a possibility of intimate correlation with mitochondria function.

As ATP is generated only in mitochondria, degradation of mitochondria according to the carcinogenesis and consecutively lowering serum content of cyclic AMP is reasonable and the phenomenon of defective immune-surveillance in cancer patients is also reasonable because of lowering concentration of seral cyclic AMP. Cyclic AMP is the same molecule with ATP, but energy level is different, 2 kilocalorie $(12 \mathrm{Kcal})$ higher than ATP $(10 \mathrm{Kcal})$ which was said by my Professor Hayaishi Osamu who is the founder of oxygenase. This may be the reason why a small amount of $1 \mathrm{mM}$ cyclic AMP has strong re-differentiation activity on cancer cell and this phenomenon has not primary correlation with genetic change. Herbal medicine (SA) $\square$ showed that most of carcinogenesis is reversible. Therefore, we have exploited re-differentiation inducing treatment. On the concluding remark, we have tried re-differentiation inducing treatment of mitochondria on cancer patients. Getting our good clinical results, our way of thinking may be right. We have pointed out the puzzle for the first time why $90 \%$ of mitochondrial DNA exists in nuclear DNA and $10 \%$ of mitochondrial DNA locate in mitochondria. Recently we have found that one of ingredients of herbal medicine (SA) include much of cyclic AMP. But it is impossible for us to reveal all the molecular basis of herbal medicine (SA) as yet. As the way of thinking in western medicine which would be hesitating to single substances, but, life phenomenon is usually depending upon complex system, for example DNA replication is depend upon 4 base substances, cytidine, thymidine, adenine and guanine, likewise, the effect of herbal medicine (SA) which is not known the molecular basis, nevertheless, important thing is experimental reproducibility from scientific position, we should not neglected the reproducing evidence of herbal medicine (SA) even if without molecular basis.

\section{Acknowledgements}

I would express sincere gratitude to Dr Thomas Seyfried, Koura M, Professor Shigeru Arichi, and many researchers whom I have cited in this paper. I am also grateful to my assistants: Tanimizu Tomoko, Sugimoto Kimito, Hayashi Nobuko, Miura Miyoko, Hosoya Kuniko, Maki Akiko, Kijima Chizuko, Jo Tokio, Ozaki Hoshiko, Harumiya Satoru and Suzuki Hideaki.

\section{Conflict of interest}

The author declares that there is no conflict of interest.

\section{References}

1. Warburg O. On the origin of cancercells. Science. 1956;123(3191):309-314.

2. Kresge N, Hanson RW, Simoni RD, et al. Sidney Weinhouse and the mechanism of ketone body synthesis from fatty acids. $J$ Biol Chem. 2005;280(23):e20.

3. Burg D, Schade AL. On respiratory impairment in cancer cells. Science. 1956;124(3215):270-272.

4. AIsenbrg AC. The glycolysis and respiration of tumors. New York Academic Press, 196:224. 
5. Peter L Pedersen. Tumor mitochondria and the Bioenergetics of Cancer Cells. Prog Exper Tumor Res. 1978;22:190-274.

6. Seyfried TN, Shelton LM. Cancer as a metabolic disease. Nutr Metab 2010;7:7.

7. Baker SG, Kramer BS. Paradoxes in carcinogenesis: new opportunities for research directions. BMC Cancer. 2007:7:151.

8. Yin S. Experts question benefits of high-cost cancer care. Medsope Today. 2011.

9. Watoson JD. To fight cancer, know the enemy. New York Times, 2009.

10. Koura M, Isaka H, Yoshida MC, et al. Suppression of tumorigenicity in interspecific reconstituted cell and cybrids. Gan. 1982;73(4):574-580.

11. Israel BA, Schaeffer WI. Cytoplasmic suppression of malignancy. In vitro Cell Dev Biol. 1987;23(9):627-32.

12. Israel BA, Schaeffer WI. Cytoplasmic mediation of malignancy. In vitro Cell Dev Biol.1988;24(5):487-490.

13. Ristow M. Oxidative metabolism in cancer growth. Curr Opin Clin Nut Metab Care. 2006;9(4):339-45.

14. Cuezva JM, Ortega AD, Willers 1, et al. The tumor suppressor function of mitochondria: translation into the clinics. Biochim Biophys Acta. 2009;1792(12):1145-1158.

15. Rous P. Surmise and fact on the nature of cancer. Nature 1959;183(4672):1357-1361

16. Roy M, Hemachandra Reddy P, Iijima M, et al. Mitochondrial division and fusion in metabolism. Curr Opin Cell Biol. 2015;33:111-118.

17. Gray MW, Franz Lang B, Cedergren R, et al. Genome structure and gene content in protect mitochondrial DNAs. Nucl Acid Res. 1981;26:865-879.

18. Gray MW. Mitochondrial evolution. Cold Spring Harb Perspect Biol 2012;4(9):a011403.

19. Serasinghe MN, Wieder SY, Renault TT, et al. Mitochondrial Division is Requisite to RAS-induced Transformation and Targeted by Oncogenic MAPK Pathway Inhibitors. Mol Cell. 2015:57(3):521-536.

20. Seyfried TN, Flores RE, Poff AM, et al. Cancer as a mitochondrial metabolic disease: implications for novel therapeutics. Carcinogenesis. 2014;35(3):515-527.

21. Kobayashi T, Tanimizu T, et al. 32 Proceeding of J. Cell Biology. 1979. $87 \mathrm{p}$

22. Sugimoto $\mathrm{K}$, Jo T, Tanimizu $\mathrm{T}$, et al. The effect of the anti-tumor herb medicine" Sun Advance" in mice. Proc Symposium WAKANYAKU.1982;15:224-227.

23. Tanimizu T, Sugimoto K, Hayashi N, et al. New approach to Chinese herb medicine, inhibition by Chinese herb medicine" Sun Advance" of SV40 transformation in mouse cells. Proc Symposium WAKAN-YAKU. 1982; 15:228-233x

24. Reitzer LJ, Wice BM, Kennel D. Evidence that glutamine, not sugar, is major energy source for cultured HeLa cells. J Biol Chem. 1979;254(8):2669-76.

25. Kobayashi T, Jo T, Hayashida S. Enhancement of immune-surveillance in Cancer Patients. American J of Acupuncture. 1987;15:25-33.

26. Hsie AW, Puck TT. Morphological Transformation of Chinese Hamster cells by dibutyryl adenosine cyclic $3 ': 5$ '-monophosphate and testosterone. Proc Natl Acad Sci USA. 1971;68(2):358-61.

27. Sato T, Friend C, De Harven E. Ultrastructual changes in Friend erythroleucemia cells treated with Dimethyl Sulfoxide. Cancer Res. 1971;31(10):1402-1417.
28. Abe H, Arichi S, Hayashi T, et al. Ultrastrucutral studies of Morris hepatoma cell reversely transformed by ginsenoside. Experimentia. 1979;35(12):1647-1649.

29. Kobayashi T, Kawakubo T. Prospective investigation of tumor markers and risk assessment in early cancer screening. Cancer. 1994;7(7):1946-1953.

30. Erick RH, Marriage TN, Ferris PJ, et al. The gonium pectoral genome demonstrates co-option of cell cycle regulation during the evolution of multicellularity. Nat commun. 2016;7:11370.

31. Takahashi K, Yamada S. Induction of pluripotent stem cells from mouse embryonic and adult fibroblast cultures by defined factors. Cell. 2006;126(4):663-676.

32. Smith JE, Muto Y, Milch PO, et al. The effects of chylomicron Vitamin A on the Metabolism of Retinol binding protein in the Rat. J Biol Chem. $1973 ; 248(5): 1544-1549$

33. Muto Y, Moriwaki H, M Ninomiya, et al. Prevention of second primary tumors by an acyclic retinoid. Polyprenoic acid in patients with hepatocellular carcinoma. $N$ Eng J Med. 1996;334(24):1561-1568.

34. Muto Y, Smith JE, Milch PO, et al. Regulation of retinolbinding protein Metabolism by vitamin A status in the Rat. $J$ Biol Chem.1972;247(8):2542-2550.

35. Chen Qi, Espey MG, Krishima MC, et al. Pharmacologic ascorbic acid concentrations selectively kill cancer cells Action as pro-drug to deliver hydrogen peroxide to tissues. Proc Natl Acad Sci USA. 2005;102(38):13604-9.

36. Chen Q, Espey MG, Sun AY, et al. Ascorbate in pharmacologic concentrations selectively generates ascorbate radical and hydrogen peroxide in extracellular fluid in vivo. Proc Natl Acad Sci USA. 2005;104(21):8749-8754.

37. Ueda M, Akita S, Torii S, et al. Effects of Solcoseryl on Flap survival Nagoya J Med Sci. 1981;44(1-2):23.

38. Udono H. Srivastava PK. Comparison of tumor specific immunogenetics of stress induced protein gp96, HSP90 and hsp 70. J Immun 1994;152:5398-5403.

39. Yoko I, Tazawa K, Wada S, et al. Induction of HSP 70 in lymphocytes by whole body hyperthermia Far-infrared Hyperthermia. Japanese $J$ Hyperthermic Oncology. 2005;21(4);209-219.

40. Hayashida S, Sugimoto K, Kobayashi T. The clinical effect of hyperthermia combined with induced hypertension chemotherapy. Gan To Kagaku Ryoho. 1984;11(6):1218-1224.

41. Hayashida S, Sugimoto K, Kobayashi T. Effect of BRM-induced systemic hyperthermia combined with Immunochemotherapy on advanced breast cancer metastasis. $5^{\text {th }}$ International Symposium on Hyperthermic Onology. 1987:361.

42. Sigler PB, Xu Z, Rye HS, et al. Structure and function in GroEL-mediated protein folding. Annu Rev Biochem. 1998;67:581-608.

43. Kiang $\mathrm{J}$ G, Wu YY, Lin MC. Heat treatment induces an increase in intracellular cyclic AMP content in human epidermoid A-431 cells. Biochem J. 1991;276(3):683-689.

44. Yasunobu Sawaji, Takashi Sato, Motoharu Seiki, et al. Heat shockmediated transient increase in intracellular 3',5'-cyclic AMP results in tumor specific suppression of membrane type 1-matrix metalloprotease production and progelatinase A activation. Clinical \& Experimental metastasis. 2000;8(2):131-138.

45. Rutherford SL, Lindqueist S. HSP90 as a capacitator for morphological evolution. Nature. 1988:396(6709):336-342.

46. Kobayashi T, Dogome M, Kawakubo T. Increase in carcinoembryonic antigen release from cancer cells by combined treatment with 
retinoic acid and low temperature hyperthermia. Int $J$ Hyperthermia 1990;6(4):785-792.

47. Kobayashi T, Correlation between tumor markers and tumor size. Cancer Detect Prev. 1987;10:81-87.

48. Kiebish MA, Han X, Cheng H, et al. Cardiolipin and electron transport chain abnormalities in mouse brain tumor mitochondria: lipidomic evidence supporting the Warburg theory of cancer. J Lipid Res. 2008;49(12):2545-2556.
49. Kenji Chamoto, Partha S, Chowdhury, et al. Mitochondrial activation chemicals synergize with surface receptor PD-1 blockade for $\mathrm{T}$ cell dependent anti-tumor activity. Proc Natl Acad Sci USA. 2017;114(5):E761-E770. 